Mycologia, 108(3), 2016, pp. 603-622. DOI: 10.3852/15-309

(C) 2016 by The Mycological Society of America, Lawrence, KS 66044-8897

\title{
The Golgi apparatus: insights from filamentous fungi
}

\author{
Areti Pantazopoulou ${ }^{1}$ \\ Department of Cellular and Molecular Biology, Centro de \\ Investigaciones Biológicas, CSIC, Ramiro de Maeztu 9, \\ Madrid 28040, Spain
}

\begin{abstract}
Cargo passage through the Golgi, albeit an undoubtedly essential cellular function, is a mechanistically unresolved and much debated process. Although the main molecular players are conserved, diversification of the Golgi among different eukaryotic lineages is providing us with tools to resolve standing controversies. During the past decade the Golgi apparatus of model filamentous fungi, mainly Aspergillus nidulans, has been intensively studied. Here an overview of the most important findings in the field is provided. Golgi architecture and dynamics, as well as the novel cell biology tools that were developed in filamentous fungi in these studies, are addressed. An emphasis is placed on the central role the Golgi has as a crossroads in the endocytic and secretory-traffic pathways in hyphae. Finally the major advances that the A. nidulans Golgi biology has yielded so far regarding our understanding of key Golgi regulators, such as the Rab GTPases RabC ${ }^{\text {Rab6 }}$ and RabE ${ }^{\text {Rab11 }}$, the oligomeric transport protein particle, TRAPPII, and the Golgi guanine nucleotide exchange factors of Arf1, $\mathrm{GeaA}^{\mathrm{GBF} 1 / \mathrm{Gea} 1}$ and $\mathrm{HypB}^{\mathrm{BIG} / \mathrm{Sec} 7}$, are highlighted.
\end{abstract}

Key words: Aspergillus nidulans, filamentous fungi, Golgi apparatus, intracellular traffic, secretion

\section{THE GOLGI APPARATUS IN EUKARYOTES: LABORS, ATTRIBUTES AND DEBATES}

Secretion is essential for organisms, both during development and for maintaining life. In rapidly growing filamentous fungi, for example, secretion maintains cell-wall expansion (Riquelme 2013); in the presynaptic neuronal axis of multicellular organisms it mediates release of neurotransmitters for body coordination (Sudhof 2013); in social insects secretion of trail pheromones mediates coordination of the colony (Noirot and Quennedey 1974, Billen and Morgan 1998, Meer and Preston 2008). Cells also synthesize continuously and sort proteins and lipids destined to replenish protein and membrane that are lost due to cell functions (e.g. endocytosis, multivesicular body sorting) or to change the composition and function of locales in response to ambient changes; for example, to provide

Submitted 5 Nov 2015; accepted for publication 1 Jan 2016.

${ }^{1}$ Corresponding author. E-mail: apantazopoulou@cib.csic.es the plasma membrane with transporters specific for the detected nutrients (Pantazopoulou and Diallinas 2007); in other cases macromolecules are being secreted to modify the cell environment or for self-protection.

In eukaryotes the central hub of the (conventional) secretory pathway is the Golgi apparatus, functionally situated between the endoplasmic reticulum (ER) and the final destinations of secretory cargo (Mironov and Pavelka 2008b). The Golgi receives biosynthetic cargo from the ER. While at the Golgi proteins are posttranslationally modified, mostly glycosylated, and membranes change their lipid composition (Mironov and Pavelka 2008a). Meanwhile the Golgi also receives recycling cargo from the endo-lysosomal system and it thus is considered a crossroads of exocytosis and endocytosis (Mironov and Pavelka 2008a). Eventually cargo is sorted into carriers to be delivered to the endosomal system, the plasma membrane or to the extracellular milieu. Overall post-translational protein modifications, remodeling of the lipid bilayer and cargo sorting appear to be the major Golgi labors in the cell (Munro 2011b).

One feature of the Golgi apparatus is intra-organelle compartmentalization. Discrete Golgi units are called cisternae. The roots of the word trace back to the Latin

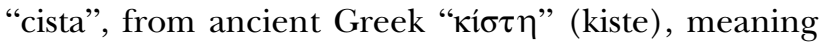
box or basket, from Proto-Indo-European kista, meaning woven container (American Heritage Dictionary of the English Language, 4th ed., "cisterna," http://www. yourdictionary.com/cistern [accessed 23 Oct 2015], Oxford Dictionaries, "cist," http:/ / oxforddictionaries. com/definition/english/cist [accessed 23 Oct 2015] and Wiktionary via the Liddell-Scott-Jones Greek-English lexicon, 8th ed.), which justifies using it to refer to individual Golgi units of any morphology, in agreement with the terminology used by (Bourett et al. 2007) for the fungal Golgi and not just to the flattened saccules present normally in higher eukaryotes. Cisternae making up the Golgi apparatus can be classified according to various interdependent characteristics, such as their content in enzymes that glycosylate biosynthetic cargo (Farquhar 1985, Graham and Emr 1991) or in proteins that regulate membrane identity (Munro 2005), their lipid composition that defines the physical properties of the bilayer (Holthuis and Menon, 2014), as well as the membrane-traffic pathways operating to and from them (Papanikou and Glick 2014). Post-translational modification-mediating enzymes and lipids form gradients through different classes of cisternae, from where cargo is considered to pass in an ordered way, such that the Golgi appears as a polarized organelle. There is an uncertainty as to 

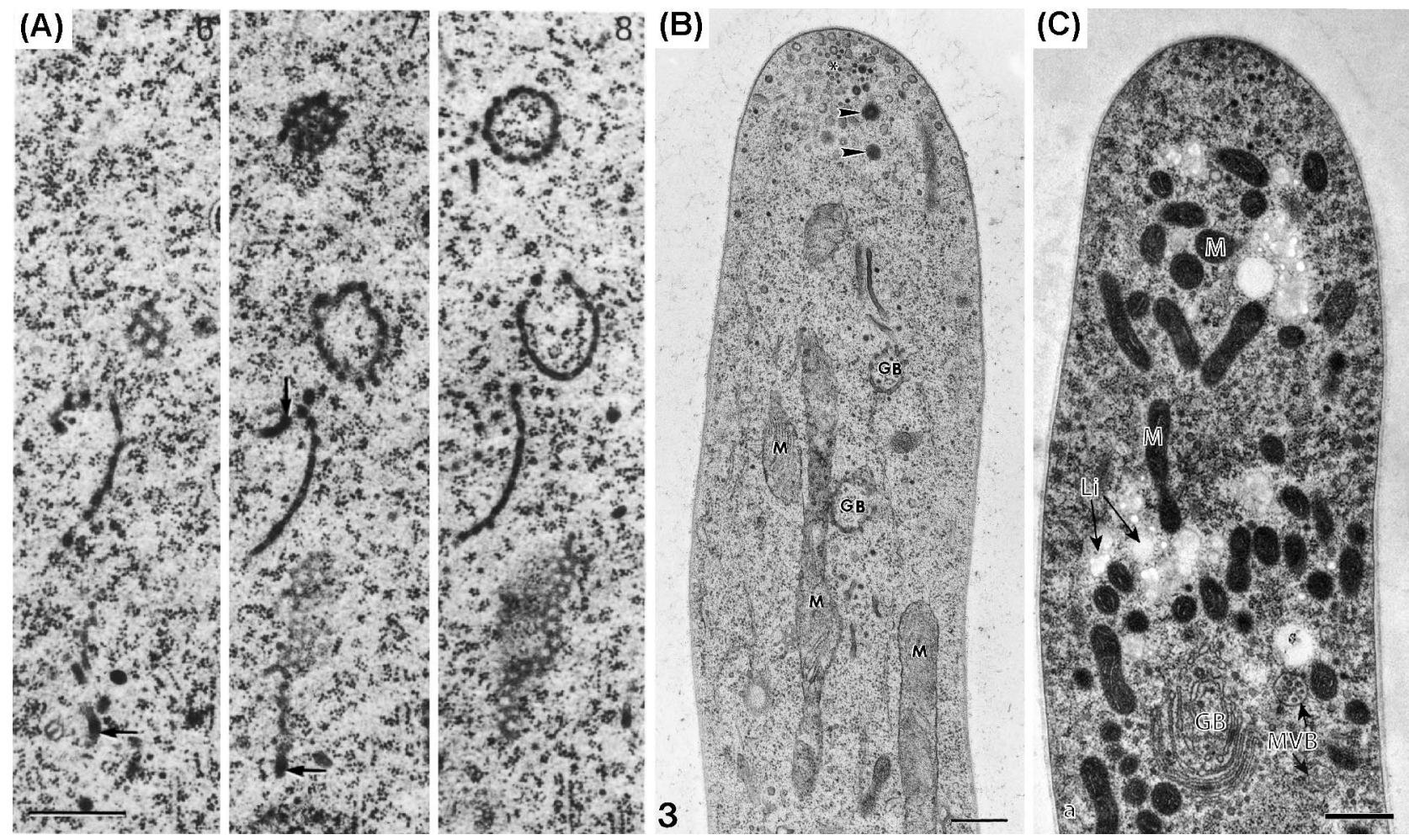

FIG. 1. Filamentous-fungal Golgi in electron micrographs. A. Golgi cisternae seen as tubules or sheets belong to the same organelle, as suggested from electron micrographs of adjacent, serial, thin sections of freeze-substituted cells of Fusarium acuminatum. Some cisternae are hollow spheres. The arrows indicate tubular elements that exhibit continuity with Golgi sheets and tubules but are wider and more electron dense. Bar $=500 \mathrm{~nm}$. Images are reproduced from Howard RJ. (1981). Ultrastructural analysis of hyphal tip cell growth in fungi: Spitzenkorper, cytoskeleton and endomembranes after freezesubstitution. J Cell Sci 48:89-103, PMID: 7196918, with permission of the Journal of Cell Science. B. Golgi cisternae (GB) in transmission-electron micrographs of near median sections through Aspergillus nidulans germ tube apical regions. Arrowheads: Woronin bodies. Asterisks: Spitzenkörper vesicles. $\mathrm{M}=$ Mitochondria. Bar $=250 \mathrm{~nm}$. Image reprinted from Momany M, Richardson EA, van Sickle C, Jedd G. (2002). Mapping Woronin body position in Aspergillus nidulans. Mycologia 94:260-266. C. The Golgi is organized in stacks $(\mathrm{GB})$ in Monoblepharis macrandra cells. Li = lipid bodies, $\mathrm{M}=$ mitochondria, MVB = multivesicular bodies. Bar $=500 \mathrm{~nm}$. Image reprinted from Dee JM, Mollicone M, Longcore JE, Roberson RW, Berbee ML. (2015). Cytology and molecular phylogenetics of Monoblepharidomycetes provide evidence for multiple independent origins of the hyphal habit in the Fungi. Mycologia 107:710-728.

how many fundamentally different Golgi compartments (i.e. groups of same-class cisternae) there are in cells. Opinions range from a minimum of two, the Trans Golgi network (TGN) from where cargo exits the Golgi and the earlier cisternae that accept ER traffic (Rothman, 1981), to three, four or more compartments (Brigance et al. 2000, Papanikou and Glick, 2014).

The Golgi is a highly dynamic organelle: many of its resident proteins cycle continuously through the ER or the endosomes, while upon treatment with Brefeldin A (BFA) (a drug inhibiting the activation of the central Golgi regulator Arf1 [Robineau et al. 2000]), the mammalian cis-/medial-Golgi merges with the ER and the TGN mixes with recycling endosomes only to reappear after BFA removal (Lippincott-Schwartz et al. 1989, Lippincott-Schwartz et al. 1991). During mitosis the mammalian Golgi undergoes fragmentation only to reorganize once mitosis is complete (Colanzi and Corda 2007).

How are diverse cisternae maintained (albeit in a dynamic equilibrium), while a continuous flow of cargo finds its way through the Golgi? This question has generated much debate for more than $50 \mathrm{y}$ now and has yielded various models intending to explain cargo passage through the Golgi. The cisterna maturation model prevails, postulating that cisternae form de novo, change their identity over time, by acquiring next stage-determining molecules and by recycling back the earlier stage molecules and eventually dissipate in secretory carriers, while cargo progresses along with the maturing cisternae toward the locale for which it is destined. However, it has gradually become obvious that this model is insufficient to explain all 
experimental observations, leading to integration of modifications to its central theme (some excellent reviews on this debate can be found in Glick and Luini [2011] and Mironov et al. [2013]. A condensed introduction to the field of Golgi biology can be found in Munro [2011b], while a detailed analysis of the status of Golgi research, up to some years ago, can be found in Mironov and Pavelka [2008b]).

\section{FILAMENTOUS FUNGAL GOLGI IN ELECTRON MICROGRAPHS}

Freeze-substitution cell fixation in electron microscopy permitted the observation of "Golgi equivalents" in various filamentous fungal species that once were believed to lack this organelle (Howard, 1981). In electron micrographs, both in Ascomycota (Fusarium acuminatum [Howard, 1981]) and Basidiomycota (Laetisaria arvalis [Hoch and Howard, 1980]), individual cisternae are dispersed in the cytoplasm, instead of forming the well-packed stacks present in animals and plants (Polishchuk and Mironov 2004). In serial thin sections, "Golgi-like elements", that sometimes were found in the proximity of mitochondria, appeared to consist of interconnected smooth-surfaced fenestrated sheets of various orientations, or fenestrated hollow spheres, as well as tubules (Howard 1981). An excellent example of such a series of sections, revealing the detailed structure of F. acuminatum cisternae, is illustrated (FIG. 1A). In Aspergillus nidulans hyphae (Momany et al. 2002, Bourett et al. 2007) (FIG. 1B), as well as in the conidiophore stalk, metulae and phialidae (Mims et al. 1988), Golgi bodies also are dispersed and their distribution is polarized toward the tip of the stalk and sterigmata. Studies in other Dikarya (such as Coprinopsis cinerea [McLaughlin 1974], Armillaria melea [Grove and Bracker 1970], Aspergillus niger and Verticilium alboatrum [Grove and Bracker 1970] and Neurospora crassa [Girbardt 1969]), although realized before the introduction of freeze-substitution for fixation of hyphae, also had suggested that elements that are not organized in stacks possibly are Golgi bodies. However, using the more distant fungal group of Monoblepharomycetes, it was shown that hyphal growth is not exclusively linked to dispersed Golgi, as hyphae of Monoblepharis macrandra were shown to possess Golgi stacks (Dee et al. 2015) (FIG. 1C). The Golgi apparatus among yeasts has similar diversification in its organization (Glick 1996): dispersed cisternae are observed in Saccharomyces cerevisiae (Preuss et al. 1992), while stacks of cisternae are present in Schizosaccharomyces pombe (Chappell et al. 1994) and Pichia pastoris (Gould et al. 1992). It has been proposed that existence of either one or the other Golgi organization reflects the underlying differences in the organization of the endoplasmic reticulum (ER) exit sites: In $P$. pastoris, where the
Golgi forms stacks, ER exit sites are discrete, confined at specific ER locales, while in $S$. cerevisiae, where the Golgi is dispersed, vesicles bud throughout the ER network (Rossanese et al. 1999). Golgins, large coiled-coil proteins at Golgi's cytoplasmic surface, together with Golgi ReAssembly Stacking Proteins (GRASPs) also have been implicated in Golgi stacking, as well as in Golgi ribbon formation in mammalian cells (Wang et al. 2003, Munro 2011a, Lee et al. 2014, Veenendaal et al. 2014), while these proteins are thought to contribute to the specificity of membrane traffic to the Golgi in yeast but also in higher eukaryotes (Behnia et al. 2007, Wong and Munro 2014). Nevertheless, the exact mechanism by which stacking is achieved is not definitively understood and even less clear remains the role this Golgi organization plays in protein secretion or other cellular function (Emr et al. 2009).

\section{IS STUDYING THE GOLGI COMPLEX IN FILAMENTOUS FUNGI WORTHY?}

The origin of the Golgi complex can be traced back to the origin of the eukaryotic cell. Most of the molecular machineries that operate in the organelle specifying its membrane identity and permitting directionality in membrane flow (e.g. the SNARES, Arf and Rab family small GTPases and their regulators, COP vesicle coats, the adaptor protein complexes and subunits of tethering complexes such as the transport protein particle [TRAPP] I/II and the conserved oligomeric Golgi complex $[\mathrm{COG}]$ ) already existed in the last common eukaryotic ancestor (Jékely 2008). That being said, it is the Golgi diversification observed among eukaryotic lineages that has been instrumental in diagnosing the elements essential for Golgi's basic labors and that has provided us with specialized tools for the study of conserved Golgi functions. For example, the fact that Golgi is dispersed in S. cerevisiae and thus individual cisternae can be chased by optical microscopy has been exploited to test in vivo whether cisternae are stable compartments or if they form de novo, change their identity over time and finally dissipate in secretory carriers (i.e. if they mature) (Losev et al. 2006, Matsuura-Tokita et al. 2006). This would have been impossible in mammalian cells because the distances of cisternae within a stack fall below optical resolution, which impedes pursuit of individual cisternae through time. However, yeast is not a cure-all: For example, unlike in mammalian cells or in long filamentous fungi where intracellular traffic is highly demanding (Schmitz and Philippsen 2011, Zhang et al. 2011, Egan et al. 2012, Penalva et al. 2012, Schuster et al. 2012, Riquelme 2013, Pantazopoulou et al. 2014, Takeshita et al. 2014), microtubules are not used in yeast for either the traffic of endosomes or of secretory carriers, 
suggesting that perhaps yeast Golgi exit and thus organization of the TGN somehow would be specialized. It is gradually becoming clear that more model systems need to be put into play to dissect an organelle as complex and as ancient as the Golgi. In addition, studies of the Golgi in filamentous fungi are permitting us to knowingly look for and interfere with secretion bottlenecks in these organisms that long have been used as cell factories without an in-depth understanding of their secretory pathways (Archer 2000, Conesa et al. 2001, Riquelme 2013, Meyer et al. 2015).

\section{THE GOLGI ARCHITECTURE UNDER THE FLUORESCENCE MICROSCOPE}

It took almost 25 y from electron micrographs (and the development of live cell microscopy techniques) before light was shed again on the filamentous fungal Golgi. In one of the first efforts, heterologous expression of yeast Yptlp (Rab1 homolog; a master Golgi regulator) fused to the green fluorescent protein (GFP) in Ustilago maydis showed labeling mostly of the hyphal apex and septa but also faintly of scattered cytoplasmic bodies (Wedlich-Soldner et al. 2002). In one of the early studies with endogenous proteins, CopA, the A. nidulans alpha subunit of the heptameric CopI coat mediating intra-Golgi and Golgi-to-ER retrograde transport (Popoff et al. 2011), was used as a reporter fused to GFP. CopA::GFP was seen to decorate hollow "doughnut-like" structures scattered in the cytoplasm (Breakspear et al. 2007), consistent with cisternae morphology in electron micrographs and resembling the 1,2-alpha-mannosidase-labeled structures that had been observed in Aspergillus oryzae (Akao et al. 2006). CopA::GFP was shown to colocalize with the red fluorescent protein (RFP)-tagged transmembrane domain of alpha-2, 6-sialyltransferase (Hubbard and Kaminskyj 2008), a Golgi enzyme. The A. nidulans GPD-mannose transporters GmtA and GmtB co-localized in Golgilike puncta (Jackson-Hayes et al. 2008, 2010). Cytosolic puncta negative for CMAC staining also were observed with some of the GFP-labeled A. oryzae Golgi-related SNARE homologs, such as AoGoslp (Kuratsu et al. 2007). The unique A. nidulans homolog of yeast Arflp/ Arf2p, ArfA (small GTPases of the Arf family are master Golgi regulators), localized to Golgi-like bodies similar to those visualized by CopA::GFP, and this localization was dependent on the ArfA myristoylation site, Gly2, as $\operatorname{ArfA}^{\mathrm{G} 2 \mathrm{~A}}:: \mathrm{GFP}$ mutant was cytoplasmic (Lee and Shaw 2008) in agreement with the notion that myristoylation ensures tight membrane association of the Arf family (Donaldson and Jackson 2011). Upon BFA treatment that prevents Golgi guanine nucleotide exchange factors (GEFs) from activating Arfl (Arfl activation is thought to be necessary for its Golgi membrane localization [Gillingham and Munro 2007]), ArfA was shown to relocalize to larger and less numerous structures than the Golgi-like bodies. The authors suggested that this phenotype was consistent with ArfA Golgi-like bodies being BFA-sensitive, strengthening the idea that they represent Golgi cisternae (Lee and Shaw 2008). Although studies with CopA and ArfA had been instructive, in both cases expression of the $g f p$-tagged alleles was driven by the alcA promoter from extra gene copies, such that a potential localization artifact, caused by non-physiological expression or a possible alteration in protein function due to the GFP tag, could not have been ruled out.

Our group used a dual strategy to label the Golgi and assess its dynamics (Pantazopoulou and Penalva 2009): On the one hand we GFP-tagged the ArfA-GEF Sec7, an essential Golgi regulator (Kaminskyj and Hamer 1998, Arst et al. 2014), by in locus gene replacement, maintaining its native promoter. The strain carrying the $\sec 7:: g f p$ allele had no apparent growth defect, which indicated that the transgene, expressed at naturally relevant levels, was functional, and thus would offer a bona fide Golgi image. On the other hand, we constructed a robust reporter, highly fluorescent and photo-stable enough to follow Golgi dynamics over time. We did this by tagging with mRFP the pleckstrin homology domain of the oxysterol binding protein $\left(\mathrm{PH}^{\mathrm{OSBP}}\right)$, which had been shown to localize at the Golgi due to coincidence detection of Arf1 and phosphatidylinositol-4-phosphate (PI4P) (Levine and Munro 2002). mRFP::PH ${ }^{\mathrm{OSBP}}$-labeled structures resembled the Sec7::GFP-labeled ones. Indeed mRFP:: $\mathrm{PH}^{\mathrm{OSBP}}$ co-localized with Sec7::GFP in growing hyphae, which suggested that $\mathrm{mRFP}:: \mathrm{PH}^{\mathrm{OSBP}}$ is also a reliable Golgi reporter. Detailed study of this reporter revealed that the Golgi apparatus in A. nidulans has these characteristics: (i) it consists of ring-shaped and fenestrated cisternae with tubular extensions, resembling in their form the cisternae seen in electron micrographs; (ii) $\mathrm{PH}^{\mathrm{OSBP}}$-labeled cisternae show a largely polarized distribution, with the bulk of fluorescence concentrating toward the tip, ahead of the leading nucleus (but with an exclusion zone [in the range of a few micrometers] immediately below the apex; FIG. 2A); (iii) cisternae are generally dispersed throughout the cytoplasm, but it is clear, both by the faint tubules seen to connect them (FIG. 2A) and by their shortrange movements that sometimes appear concerted, that cisternae are part of a network, rather than isolated; (iv) this network is highly dynamic in at least two ways: First, cisternae undergo continuous morphological transformations, changing shapes, while fluorescence intensity fluctuates and seems to redistribute between adjacent structures, and, second, cisternae have short-range non-directional movements and 
sometimes external forces would appear to pull or stretch them (Pantazopoulou and Penalva 2009). Expression of the artificial mRFP:: $\mathrm{PH}^{\mathrm{OSBP}}$ reporter did not have any effect on hyphal growth, and furthermore, mRFP::PH ${ }^{\mathrm{OSBP}}$ seemed to monitor Golgi activity, as, in response to anaerobiosis and/or mechanical pressure resulting from mounting hyphae on slides, it re-localized rapidly to the cytoplasm (mRFP:: $\mathrm{PH}^{\mathrm{OSBP}}$, similar to Sec7::GFP, is a peripheral membrane protein, expected to become cytoplasmic when its localization requirements on membranes are not met). This made clear that, so as to be meaningful, studies of an organelle as dynamic as the Golgi should be carried out in undisturbed growing hyphae (for example, in liquid medium observed by an inverted microscope in chambers kept at the appropriate temperature and in illumination conditions minimizing photodamage). It soon became obvious that Golgi architecture as observed by fluorescence microscopy correlated with growth speed, in that perturbations of Golgi integrity were readily reflected in apical extension (Pantazopoulou and Penalva 2009, 2011). Moreover, alterations in Golgi organization, achieved, for example, by modifying the ER-to-Golgi interface flux using conditional mutants $\left(s a r A^{\text {ts }}, r a b O^{\text {ts }}, s e d V^{\text {ts }}\right.$, see also below), resulted in tip morphology alterations. This revealed a potential way to achieve hyphal depolarization, which is necessary for shifts in the morphogenesis plan during, for example, appressorium formation in Magnaporthe oryzae or conidiophore development in A. nidulans (Harris 2013, Pinar et al. 2013, Hernandez-Gonzalez et al. 2015) .

\section{DECIPHERING GOLGI COMPARTMENTALIZATION IN HYPHAE}

A functional Golgi unit in higher eukaryotes consists of diverse cisternae that are organized in a stack. Cisternae have varying biochemical characteristics that correlate with their relative position in the stack. A typical mammalian interphase cell includes 40-100 stacks connected by membrane tubules to form a perinuclear Golgi ribbon, while in invertebrates stacks do not form a ribbon but instead are dispersed in the cytoplasm (Wei and Seemann 2010). In Drosophila melanogaster dendrites, cis-, medial- and trans-Golgi cisternae appear to be disconnected (not forming stacks) in vivo (Zhou et al. 2014). In microsporidia the Golgi is a tubular network connected with the ER and the plasma membrane that comes in two morphologies (plane or varicose tubules [Beznoussenko et al. 2007]). How does filamentous fungal Golgi (that consists of cisternae that in most cases are [i] scattered in the cytoplasm, [ii] not organized in stacks, [iii] frequently interconnected by tubules and [iv] polarized toward the growing apex) relate to these examples with regard to its compartmentalization and the organization of the different compartments that build up the cell's Golgi apparatus? One important question was whether absence of stacks in hyphae is due to dispersion of cisternae with distinct identity or if it reflects a potential lack of functional compartmentalization in fungal Golgi. In other words: Do dispersed cisternae in fungi have the biochemical differences observed in organisms with stacks?

The early and late Golgi in A. nidulans.-In S. cerevisiae fluorescent-tagged protein markers characteristic of the late (corresponding to trans in cells with stacks) or the early (corresponding to cis) Golgi are present in distinct sets of cisternae scattered over the cytoplasm that are seen as puncta resolvable by optical microscopy (Wooding and Pelham 1998).

In A. nidulans a compartment labeled with the Sed5 syntaxin homolog, SedV, segregates from the $\mathrm{PH}^{\mathrm{OSBP}}$ labeled compartment (Pantazopoulou and Penalva 2011). Further localization studies with other Golgi markers revealed that indeed we can distinguish two main Golgi territories. For example, GFP::RerA, homo$\log$ of Rer1, a membrane protein receptor responsible for the retrieval of ER resident proteins from the Golgi (Sato et al. 1997), showed extensive co-localization with mCherry::SedV and clear segregation from mRFP::PH ${ }^{\mathrm{OSBP}}$ (Pinar et al. 2013) (FIG. 2A). GeaA:: GFP, a member of the family of early Golgi Arfl-GEFs (GBF1/Gea), also co-localized substantially with mCherry::SedV, while segregating from mRFP:: $\mathrm{PH}^{\mathrm{OSBP}}$ (Arst et al. 2014). GFP::TlgB (TlgB is the Tlg2/ syntaxin16 homolog) co-localized with mRFP:: $\mathrm{PH}^{\mathrm{OSBP}}$ at the late territory, while mRFP::TlgB segregated from GFP::SedV (Pinar et al. 2013). Sec7::GFP, member of the family of late Golgi Arfl-GEFs (BIG/Sec7), co-localized with mRFP::PH ${ }^{\mathrm{OSBP}}$ (Pantazopoulou and Penalva 2009). GrhA, the homolog of GRASP65/ Grh1, involved in early Golgi assembly by COPII vesicles (Behnia et al. 2007), segregates from $\mathrm{PH}^{\mathrm{OSBP}}$, in addition, GrhA-labeled structures collapse in large aggregates in the presence of BFA (similar to the collapse seen with ArfA [Lee and Shaw 2008]), suggesting that GrhA localizes at the Golgi (collapse into large aggregates is a characteristic response of the Golgi but not of the ER to BFA treatment; see also below and [Pantazopoulou and Penalva 2009]). A. oryzae GrhA homolog substantially co-localized with AoVip36 and AoEmp47 (Hoang et al. 2015), two cargo receptors with L-type lectin domains involved in ER to Golgi trafficking of N-linked glycoproteins. Thus SedV, RerA and GeaA substantially co-localize at one class of cisternae (where GrhA might also localize), while 
(A)

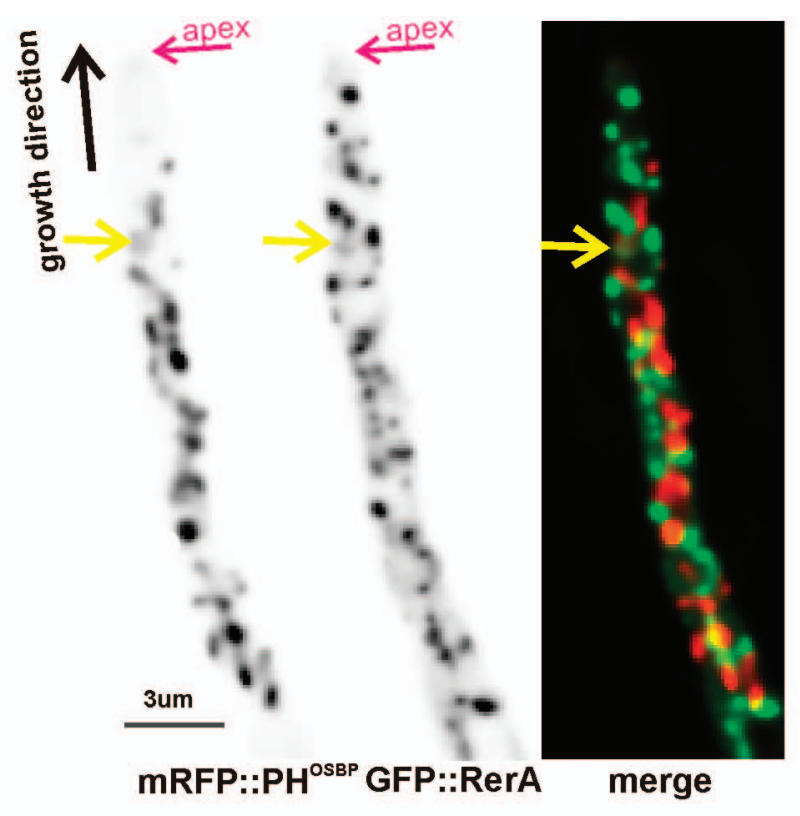

(B) Golgi organization in a tip at time point $x 1$

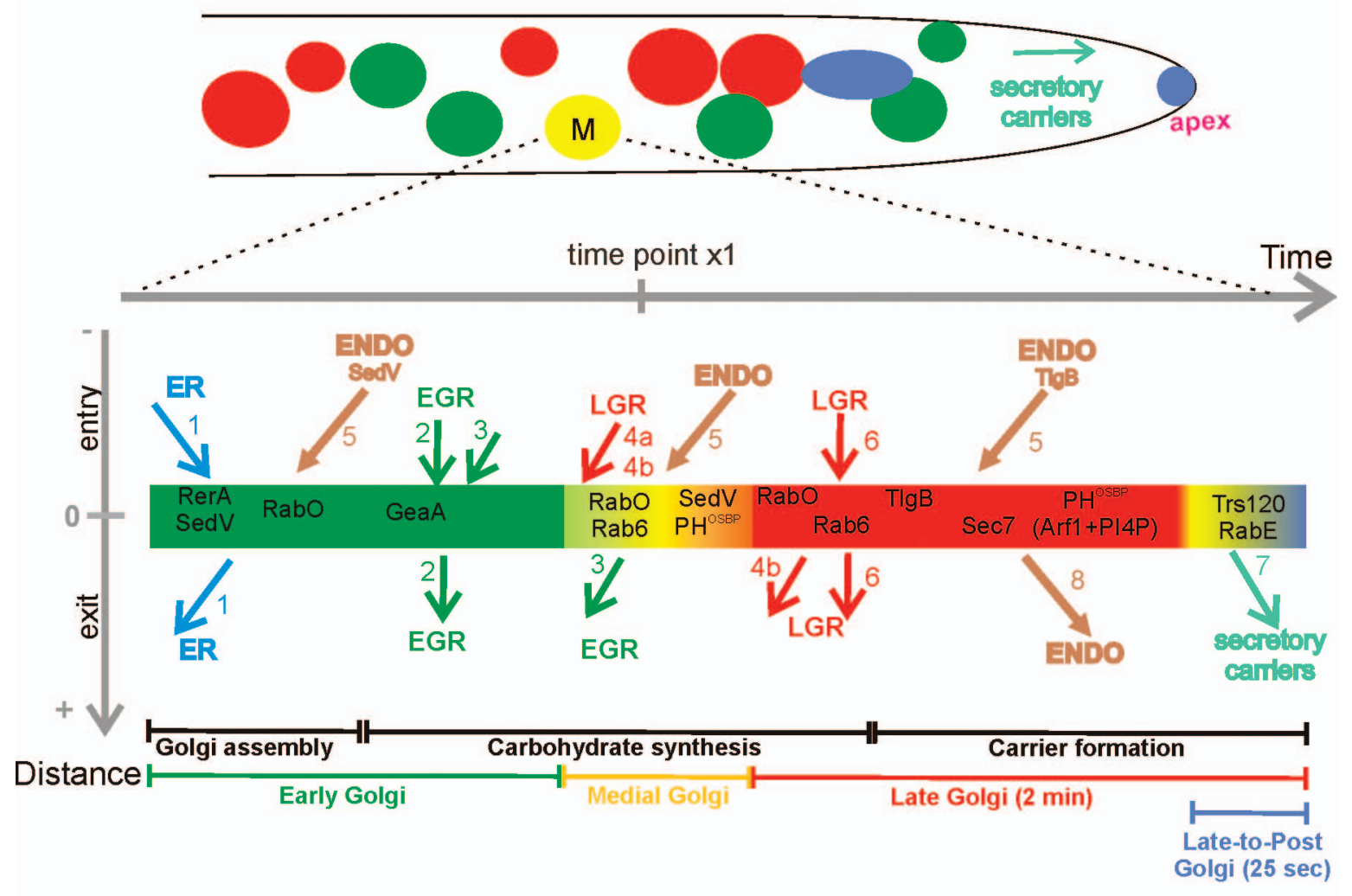

Graph: Life cycle of cisterna M

FIG. 2. Filamentous-fungal Golgi compartmentalization. A. Wide-field fluorescence micrographs of early and late Golgi compartments in the Aspergillus nidulans tip cell (in the region ahead of the leading nucleus). The late Golgi is labeled by the mRFP::PH ${ }^{\mathrm{OSBP}}$ reporter, the early Golgi is labeled by GFP::RerA (see text for details). Note how GFP::RerA-containing cisternae almost reach the apex, while mRFP:: $\mathrm{PH}^{\mathrm{OSBP}}$-containing cisternae appear to be excluded from the subapical region. The late Golgi compartment is clearly a network of interconnected cisternae, in that faint tubules can be seen to connect the globular, more intensely fluorescent, cisternae. Note that early and late Golgi cisternae intermingle but they are clearly segregated entities. 
Tlg2, $\mathrm{PH}^{\mathrm{OSBP}}$ and Sec7 co-localize at a different class of cisternae (FIG. 2B). The markers we used were functionally suggestive: The only two A. nidulans Golgi syntaxins SedV and Tlg2 (López-Berges et al. 2016) mark two distinct compartments by the conserved Arfl-GEFs GeaA and Sec7, members of the cis/early and trans/ late subfamily of Golgi Arf1-GEFs, respectively, (Arst et al. 2014) co-localize with the relevant early or late syntaxin; the RerA receptor responsible for the retrieval of ER resident proteins early in the secretory pathway (Sato et al. 1997) is confined with the early Golgi syntaxin and the early Golgi Arfl-GEF, as expected; the coincidence of PI4P with activated Arf1, both of which have a pivotal role in Golgi exit (D'SouzaSchorey and Chavrier 2006, Daboussi et al. 2012, De Matteis et al. 2013), is detected by the $\mathrm{PH}^{\mathrm{OSBP}}$ reporter only where the late Golgi syntaxin and the late ArflGEF reside. It is important to note that for each of the compartments both transmembrane (SedV, RerA, Tlg2) and peripheral membrane proteins (GeaA, $\left.\mathrm{Sec} 7, \mathrm{PH}^{\mathrm{OSBP}}\right)$ were tagged and localized, minimizing the possibility of artifacts related to the membraneassociation mechanism of the hybrid proteins. Accordingly we named the SedV/GeaA/RerA compartment

$\leftarrow$

Yellow arrow indicates a faintly labeled medial cisterna, where mRFP::PH ${ }^{\mathrm{OSBP}}$ and GFP::RerA colocalize. Images are sum projections of deconvolved z-stacks. Metamorph (MolecularDevices) and Huygens Professional Deconvolution (SVI) image analysis software was used. B. Upper panel. A scheme depicting Golgi compartmentalization in filamentous fungi at a time point $\times 1$. Two main compartments are observed: in the early compartment (in green) proteins that are predicted to act early (SedV, RerA, GeaA) in the secretory pathway colocalize. In the late compartment (in red) proteins that are predicted to act late (TlgB, $\mathrm{PH}^{\mathrm{OSBP}}$, Sec7) in the secretory pathway colocalize. Protein markers from different compartments mainly segregate (see A). Early and late Golgi markers colocalize in a minority of cisternae, the medial (yellow) cisternae. A fraction of the late Golgi cisternae are labeled by Trs120 and RabE ${ }^{\text {Rab11 }}$ (purple), and we have shown with time lapses that these cisternae gradually lose Golgi identity, acquiring post-Golgi identity, until they dissipate into secretory carriers that are transported to the apex, presumably to maintain polarized growth. Lower panel. Depiction of the lifecycle of an individual cisterna over time (cisterna "M" of the upper panel), based on data and hypotheses. The x-axis represents time. Cisternae are transient (Pantazopoulou et al. 2014, unpubl). Late Golgi cisternae mature to RabE ${ }^{\mathrm{Rab} 11 / Y p t 31}$-containing post-Golgi carriers (Pantazopoulou et al. 2014, Pinar et al. 2015) and early Golgi cisternae mature to medial and then to late Golgi (Pantazopoulou and Peñalva unpubl). Golgi Rabs partially localize at the early and/or the late Golgi. Because Rabs are determinants of identity, this indicates that the attributes of cisternae, relating to the traffic pathways to and from them, cannot be accurately described by their simple classification as early, medial and late. The scheme depicts a highly hypothetical, alternative classification of cisternae into the Golgi assembly, carbohydrate synthesis and carrier formation stages based on Day et al. (2013). The early Golgi should exchange traffic with the ER (1) (see text for details) and thus be, at least for some part of its lifetime, at the Golgi assembly stage. After its assembly an early Golgi cisterna would participate in intra-Golgi traffic pathways that would result in its enrichment in glycosylation enzymes by the delivery of early Golgi resident proteins (EGR) originating from other early (2) and/or medial (3) Golgi cisternae (carbohydrate synthesis stage). The lipid remodeling that most possibly takes place throughout might at a point trigger the recruitment by the early Golgi of peripheral membrane late Golgi-determinant proteins (LGR) from the cytoplasm (such as Sec7) (4a) resulting in the transformation of early to medial (and then late) Golgi. Hypothetically late Golgi transmembrane proteins (LGR), such as TlgB, might be supplied biosynthetically and distributed by rapid partitioning to late Golgi lipid bilayers through (hypothetical) connections between heterologous Golgi cisternae or they might be delivered by retrograde traffic from the late Golgi to the early/medial Golgi (4b). We know that retrograde pathways most probably operate from the endosomes (ENDO) and/or the post-Golgi endosome (PGE) toward both the early and the late Golgi (5), with the Golgi syntaxins SedV or TlgB being implicated in each step (López-Berges et al. 2016). These routes might even contribute to maturation: In a hypothetical scenario late Golgi resident proteins escaping the Golgi along with cargo bound to the endo-lysosomal system would have the chance to be retrieved from the endosomes and to be recycled back to maturing (early/medial) cisternae (5), contributing to cisternae transformation. Lipid segregation or COPI-dependent retrograde traffic should segregate early from late compartments in the medial cisternae (3). Intra-Golgi traffic based on COPI and/or RabC might take place up to the initial phases of the late Golgi (6). At some point, however, cisternae would be committed to carrier formation. We have observed the $\mathrm{HypA}^{\text {Trs120}}$-dependent maturation of cisternae to $\mathrm{RabE}^{\mathrm{Rab11}}$-containing carriers bound to the apical plasma membrane (7)

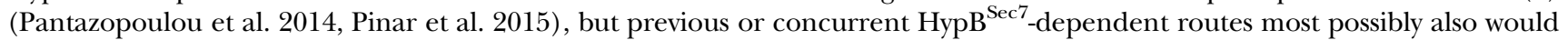
regulate the transport of cargo bound to the endosomes (8). Arrows are colored according to the origin (for entry routes) or the destination (for exit routes) compartment: blue for the ER, brown for endosomes, red for the late Golgi, green for the early Golgi and mint green for secretory carriers toward the SPZ. Routes involving the medial Golgi are colored according to their individual early or late components. $\mathrm{x}$ - and $\mathrm{y}$-axis shall be used to interpret arrows: Because of their directionality and slope arrows contain information indicating whether routes connect later with earlier (and vice versa) or equivalent (for vertical to the $\mathrm{x}$-axis arrows) compartments. 
"early" (cis) and the Tlg2/Sec7/PH OSBP "late" (trans), depending on the order in which the relevant Golgi markers are predicted to act in the secretory pathway (FIG. 2B).

The medial Golgi.-Segregation of the early from the late Golgi markers, however, is not complete. mRFP:: $\mathrm{PH}^{\mathrm{OSBP}}$ co-localizes with GFP::SedV to some extent (20\% of mRFP::PH ${ }^{\mathrm{OSBP}}$ bodies have detectable GFP:: SedV [Pantazopoulou and Penalva 2009]), which is consistent with the transient co-localization observed between the early and late Golgi markers during cisternal maturation in yeast (Losev et al. 2006, Matsuura-Tokita et al. 2006). Although a putative intermediate in cisternal maturation, this medial compartment may as well classify as a third basic entity of the fungal Golgi: It is distinct in composition from the early or the late compartment and, due to its different composition in molecular traffic determinants, entry/ exit pathways to/from the medial cisternae would be different from those in earlier or later cisternae. It might also be that, on the medial compartment, factors typically viewed as early or late Golgi residents are brought close such that interactions between them have an opportunity to occur. For the time being it would be informative to determine whether markers other than SedV::GFP and mRFP:: $\mathrm{PH}^{\mathrm{OSBP}}$ localize at the medial Golgi.

Is classification of the Golgi compartments as early or late sufficient to describe them functionally? The example of localization of the Golgi Rabs.-Deciphering compartmentalization becomes more complex as localization of some Golgi components may come in continuous gradients instead of steep thresholds. In some cases gradients of different markers neither overlap completely nor segregate completely. For example, although Rab proteins are well-established determinants of membrane identity that regulate membrane trafficking (Barr 2013, Casanova et al. 2013), RabC, the A. nidulans homolog of Ypt6/Rab6 regulating endosome-to-Golgi, intra-Golgi and Golgi-to-ER retrograde traffic (Liu and Storrie 2012) partially localizes at both the early and late Golgi entities (Pantazopoulou and Penalva, 2011). A similar localization also has been reported for yeast Ypt6 (Suda et al. 2013). Moreover, it seemed that RabC localization is influenced by the distance from the hyphal tip: Close to the tip, where most late Golgi cisternae are found and immediately below the apex, where exocytosis predominates, GFP-RabC localizes mostly in a tubular network containing mCherry-SedV, while away from the tip RabC is in discrete cytoplasmic bodies containing $\mathrm{PH}^{\mathrm{OSBP}}$ (Pantazopoulou and Penalva 2011). Similarly localization of RabO, the Ypt1/Rab1 homolog regulating fusion of ER-derived vesicles to form the Golgi (Short et al. 2005), depends on the distance from the apex: At the tip RabO mostly co-localized with SedV at the early Golgi, whereas away from the tip RabO partially co-localized with both SedV at the early and $\mathrm{PH}^{\mathrm{OSBP}}$ at the late Golgi (Pinar et al. 2013). These data suggested that the Golgi apparatus in long hyphae is not uniform. On the contrary, cisternae location within the cell relative to the growing apex influences their organization. The dependence of Golgi organization on its position in the hypha may reflect possible quantitative differences in Golgi activity depending on the proximity to the apex. Golgi activity in turn may depend on biosynthetic activity (Some data indeed indicate that there are differences in gene expression depending on the nuclear position in hyphae [Kohli et al. 2008, Herrero-Garcia et al. 2015]).

Co-localization quantification methods.-To assess such complex localizations we have used several methods: First, we have been counting how many cisternae show co-localizing signals comparing to the total cisternae number. To do this we determine whether the shapes of cisternae in the two channels appear similar through the $\mathrm{x}$-, $\mathrm{y}$ - and $\mathrm{z}$-axis in z-stacks of images to avoid overestimating co-localization due to mere overlaps resulting from the projection of a 3D hypha in two dimensions. In this way we collect binary data on the existence/absence of any degree of apparent colocalization, but we cannot distinguish between potentially very different cases, such as robust co-localization from co-localization of very low with very high signals (very low or high relative to the intensity distribution in each channel). Thus we also have been making use of more sophisticated co-localization analysis tools, especially JACoP plugin (Bolte and Cordelieres 2006) of Image J (Schneider et al. 2012) and Li's intensity correlation analysis plots ( $\mathrm{Li}$ et al. 2004) therein (for an example of the use of the plots, see Pinar et al. [2013]). Still intermediate situations, where markers partially colocalize, are hard to assess accurately in a quantitative manner. In part to circumvent that problem we have been assessing co-localization of markers upon BFA treatment, which triggers Golgi collapse in large aggregates (Lee and Shaw 2008, Pantazopoulou and Penalva 2009). Of note, SedV and $\mathrm{PH}^{\mathrm{OSBP}}$ localize at distinct BFA aggregates (Pantazopoulou and Penalva 2011), suggesting that these aggregates somehow maintain distinct identities. This method revealed that, for example, RabC localizes partially at both late and early Golgi aggregates while RabO predominates at early Golgi aggregates, although localization at the late Golgi of both of these Rabs in the absence of BFA seemed similar, increasing in tip-distal regions (Pantazopoulou and Penalva 2011, Pinar et al. 2013). 
Although we do not currently understand the mechanism of Golgi aggregation upon BFA treatment, it seems logical to assume that differences in BFA reflect some of the existing differences in non-treated cells and thus BFA has been used to assist us in further classifying our ambiguous markers. Improvement in quantification methods, super-resolution microscopy, as well as time-resolved studies of more markers may reveal subdomains in the main Golgi compartments we have defined so far. Co-visualization of more than two markers each time also might help understand the complex localization profiles of proteins that partially localize at both early and late Golgi.

Little is known on Golgi compartmentalization from other filamentous fungi. In Neurospora crassa, the homolog of yeast Golgi-localized PMR1 $\mathrm{Ca}^{+{ }^{+}}$-ATPase localizes at cytosolic puncta that do not co-localize with the Golgi-associated retrograde protein (GARP) complex subunit VPS-52, suggesting that there are disconnected Golgi subcompartments in hyphae (Bowman et al. 2009). Recently heterokaryons were used for colocalization studies of Golgi determinants and it was found that YPT-1 partially co-localizes with presumed early (USO-1, VRG-4) and late (SEC-7, VPS-52) Golgi markers (Sanchez-Leon et al. 2015). Late Golgi marker SEC-7 and the GARP complex subunit VPS-52 also were found to partially colocalize.

Overall these data show that there is Golgi compartmentalization in filamentous fungi. In A. nidulans there are clearly at least two separate entities where essential determinants of the Golgi normally cocluster: the early and late Golgi compartments that maintain their distinct identities even in the large Golgi-aggregates triggered by BFA. A third compartment, where at least some of the early and late Golgi markers overlap, reflects the continuity over time of the early and late cisternae (i.e. that early cisternae mature to late cisternae). Finally the thresholds delimiting fundamentally distinct functional entities may not completely coincide with the compartment limits set by the markers that, when studied in pairs, determine the early from the late Golgi territories: For example, Golgi Rab proteins seem to transcend the borders of early/late Golgi, suggesting further subcompartmentalization in A. nidulans.

\section{GOLGI FUNCTIONAL ENTITIES: THE GOLGI AS CENTRAL HUB} OF INTRACELLULAR TRAFFIC PATHWAYS

Because functionality of the Golgi compartments is ultimately conferred by the concurrent localization of numerous proteins and lipids, the localization of a handful of markers cannot be sufficient to understand the functional significance of compartmentalization. To integrate data from different organisms, Day,
Staehelin and Glick recently proposed that three fundamentally different classes of compartments can be distinguished based on the pathways operating to and from them (Day et al. 2013, Papanikou and Glick 2014): (i) the cisternal assembly stage, during which cisternae accept COPII biosynthetic traffic from the ER and deliver back to it COPI-coated vesicles, recycling trafficking components and ER resident proteins, (ii) the carbohydrate synthesis stage, where intra-Golgi transport takes place via COPI-dependent traffic exchange and (iii) the carrier formation stage, during which cisternae receive endosome traffic and form clathrin-coated carriers bound to the endosomes and secretory carriers bound to the plasma membrane (Paczkowski et al. 2015).

The three compartments, early, medial and late, we observe in the A. nidulans Golgi most possibly do not reflect these functionally distinct entities. Yet some functional characteristics of the cisternae deduced from the data can be orientating (consult also FIG. 2B).

First, the early Golgi compartment at least for a great part of its lifetime must be at the Golgi assembly stage, as at least two of its residents, RerA and SedV, relocalize to the ER after prolonged BFA treatment or when ER exit is blocked by SarA ${ }^{\text {Sarl }}$ conditional mutants (Hernandez-Gonzalez et al. 2015), suggesting that this compartment directly exchanges material with the ER.

Second, the late compartment at least in part must be at the carrier formation stage, in that we have shown that it eventually dissipates into secretory carriers. A. nidulans $\mathrm{RabE}^{\mathrm{RAB} 11}$ is the sole homolog of yeast Ypt31 and Ypt32 that regulate polarized secretion (Ortiz et al. 2002, Lipatova et al. 2008). We found that RabE labels post-Golgi carriers (for details see below and Pantazopoulou et al. [2014]). During the last $25 \mathrm{~s}$ of its 2-min lifetime the $\mathrm{PH}^{\mathrm{OSBP}}$ late compartment loses $\mathrm{PH}^{\mathrm{OSBP}}$ (and Sec7) signal, while being enriched in $\mathrm{RabE}^{\mathrm{RAB} 11}$. This process concludes with the formation of post-Golgi RabE carriers of long-range motility that are targeted to the Spitzenkörper (SPZ) (Pantazopoulou et al. 2014). We therefore deduce that, when $\mathrm{PH}^{\mathrm{OSBP}}$ and Sec7 co-localize with RabE, the late Golgi must be at the carrier formation stage, gradually losing Golgi identity while acquiring post-Golgi identity. Based on recruitment of the clathrin-coated-vesiclespecific adaptor GGA on the TGN simultaneously with the peak of Sec7 in yeast (Daboussi et al. 2012, McDonold and Fromme 2014), it is possible that this endosome-bound traffic leaves the TGN before RabE carriers (RabE signal peaks later than Sec7 in A. nidulans), thus the duration of the carrier-formation stage might be longer than the period during which RabE stays at the TGN. Shift of the conditional hypB5 $5^{\sec 7 t s}$ mutant (Sec7 regulates at the TGN the formation of clathrin- and GGA-coated vesicles bound to 
endosomes) to the restrictive temperature results in Vps10, the sorting receptor of vacuolar proteases that normally cycles between the Golgi and the endosomes, accumulating at the late Golgi (Pantazopoulou and Penalva 2011). This is consistent with Sec7 playing a role in the generation from the late Golgi of Vps10-containing carriers bound to the endosomal system. Because cargo sorting appears to take place while at the carrier formation stage, we can conclude that the late Golgi in A. nidulans resembles the TGN of other cells (De Matteis and Luini 2008, Guo et al. 2014).

Functionally discriminating between cisternae based on whether they receive retrograde traffic from endosomes has proven to be complicated in A. nidulans. The TlgB-labeled late Golgi compartment most possibly receives endosomal traffic: Tlg2, yeast's homolog of the A. nidulans $\mathrm{TlgB}$, and its mammalian homolog, syntaxin 16, both have been implicated in the formation of SNARE bundles regulating fusion with the TGN of vesicles derived from the endosomes (Abeliovich et al. 1998, Amessou et al. 2007). Association of TlgB with the SNARES Vtil, TlgA and SynA observed with $A$. nidulans proteins (López-Berges et al. 2016) is consistent with such a role. A. nidulans $r a b C \Delta$ largely re-localizes Vps10 from the Golgi to a cytoplasmic haze, which suggests that RabC regulates an endosome-to-Golgi retrograde pathway. $\operatorname{tg} B$ is dispensable but demonstrates synthetic lethality with $\operatorname{rabC\Delta }$, suggesting a RabC-independent role of $\mathrm{TlgB}$ in retrograde traffic (Pantazopoulou and Penalva 2011). Although TlgB must be implicated in retrograde traffic from the endosomes to the Golgi, $\operatorname{tg} B \Delta$ has a minor effect on the localization of the exocytic R-SNARE SynA (the Snc1p/Snc2p homolog) at an apical crescent (López-Berges et al. 2016) despite the fact that this localization depends on coordination of SynA continuous endocytosis at the subapical endocytic ring with its subsequent redelivery to the apical plasma membrane (Lewis et al. 2000, Valdez-Taubas and Pelham 2003, Taheri-Talesh et al. 2008, Pantazopoulou and Penalva 2011) likely via the Golgi (Pinar et al. 2013, López-Berges et al. 2016) as in yeast (Lewis et al. 2000). $\operatorname{tg} A \Delta$ on the other hand somehow disturbs SynA localization at the apex and reduces its overall presence at the tip, suggesting that it affects SynA recycling more than $\operatorname{tg} B \Delta$. Consistently TlgA can interact both with SedV (the early Golgi syntaxin) and TlgB (the late Golgi syntaxin) (López-Berges et al. 2016), suggesting that TlgA also may participate in a TlgBindependent pathway to the Golgi. Moreover, SedV, apart from having been involved in a retrograde pathway through TlgA-dependent SNARE bundles, has been found further to form TlgA-independent bundles with endosomal snares (Syn8-dependent), suggesting that it perhaps also participates in a retrieval pathway to the Golgi from a later endosomal compartment (López-Berges et al. 2016). This would explain why SynA substantially localizes at the apex even in $\operatorname{tg} A \Delta$ and is consistent with the double $\operatorname{tg} A \Delta \operatorname{tg} B \Delta$ mutant growing like the wild type. Consistently a mutant debilitating SedV demonstrates synthetic lethality with $\operatorname{tg} B \Delta$, further suggesting independent roles of SedV and $\mathrm{TlgB}$ in retrograde traffic from the endosomes to the Golgi. In summary, retrograde pathways from the endosomes to the Golgi have been proposed to use at least three distinct SNARE bundles in A. nidulans, one involving the late Golgi syntaxin and two involving the early Golgi syntaxin (López-Berges et al. 2016), suggesting that cisternae at both the Golgi assembly and at the carrier formation stage are apt to receive endosomal traffic.

During the carbohydrate synthesis stage intra-Golgi transport presumably takes place, resulting in the exchange of Golgi resident glycosylation enzymes between cisternae and in the formation of enzyme gradients (Papanikou and Glick 2014). During this stage COPI carriers are thought to bud from some cisternae and fuse with other. Directionality during COPIdependent intra-Golgi traffic that would result in asymmetric Golgi enzyme distribution may be conferred by continuous lipid remodeling in cisternae, combined with the partition of proteins in favorable lipid environments (Patterson et al. 2008, Day et al. 2013, Papanikou and Glick 2014). Transfer of material from older to younger cisternae is thought to be achieved as older cisternae lose their ability to accept COPI carriers while younger cisternae acquire this ability. This is mostly uncharted territory in A. nidulans. It is logical to assume that, while cisternae mature (Pantazopoulou and Peñalva unpubl, see also below), at some point the early Golgi becomes competent at accepting COPI vesicles recycling Golgi residents, such as glycosylation enzymes, that are being extracted from a later cisterna en route to the carrier-formation stage (FIG. 2B). The medial Golgi should be part of this stage, when viewed from the cisternal maturation standpoint, because it is an intermediate compartment that has to gradually undergo domain segregation and send early Golgi resident-containing membranes to retrograde pathways. The late Golgi would participate in intra-Golgi traffic if, for example, newly formed late Golgi needed further transformation before it reached the carrierformation stage or if late Golgi residents had to be sent to earlier cisternae, although these possibilities are clearly hypothetical and should be subject to experimentation. If these assumptions are true, the early, medial and late Golgi, for some period of their lifetimes, would participate in COPI-dependent intraGolgi exchange and thus would be part of what is 
considered the carbohydrate assembly stage. A study of COPI localization (and of glycosylation enzymes) across Golgi subcompartments should be informative on intra-Golgi transport and will be reported elsewhere (Hernandez-Gonzalez, Pantazopoulou and Peñalva unpubl). Tubules observed throughout the Golgi might be evidence of intra-Golgi transport in A. nidulans, although we have not determined whether there might be tubule-mediated transport of cargo, resident proteins or both. Rab6 is known to regulate intra-Golgi transport and in rabC $\Delta$ cells the $A$. nidulans Golgi is fragmented, perhaps as a consequence of perturbed intra-Golgi pathways (Pantazopoulou and Penalva 2011).

A near-complete functional characterization would require the characterization of lipid components in the Golgi apparatus. Within the Golgi exists the demarcation line of two membrane territories with distinct properties: thin and loose bilayers at the ER and the cis-Golgi and thick, rigid bilayers, of negative cytoplasmic charge at the trans-Golgi and the plasma membrane (Holthuis and Menon 2014). This transition is mediated by sphingolipid and sterol supply so lipid homeostasis proteins have a central role in it. Lipid homeostasis at the Golgi has important roles in exocytic cargo sorting (Hankins et al. 2015b). Although this is largely an unexplored field in filamentous fungi, the GFP::Lact-C2 reporter binding to phosphatidylserine (PS) recently was used to visualize PS distribution in A. nidulans (Penalva 2015, Schultzhaus et al. 2015). In tip cells, when expressed at relatively high levels, this reporter labels Golgi-like cytosolic structures apart from the SPZ suggesting that PS is enriched on the cytosolic face of these cisternae. PS faces the lumen of the ER, while it is translocated at the cytosolic leaflet by the action of flippases at the trans Golgi (Hankins et al. 2015a). The A. nidulans phospholipid translocases (flippases) DnfA (homologue of yeast Dnf1/2) and DnfB (homolog of yeast Drs2) localize at the SPZ and at cytosolic structures, where they co-localize with the late Golgi marker $\mathrm{PH}^{\mathrm{OSBP}}$, with DnfB showing a more prominent localization to the latter compartment (Schultzhaus et al. 2015). Although the flippases were not formally shown to segregate from early Golgi markers, these data suggested that differences in lipid homeostasis regulation and thus lipid content would further differentiate the early from the late Golgi in A. nidulans. Non-vesicular lipid traffic mediated by lipid transfer proteins may collaborate with the action of flippases to establish lipid asymmetry in membranes (Panatala et al. 2015). OshA, the A. nidulans homolog of yeast Osh1 (a member of the yeast oxysterol binding proteinrelated proteins that regulate lipid homeostasis and are implicated in non-vesicular transport of sterols [de Saint-Jean et al. 2011], ceramide [Kajiwara et al. 2014] and phosphatidylserine [Maeda et al. 2013, Moser von Filseck et al. 2015]), appears to localize in Golgi cisternae, similarly to its yeast counterpart (Levine and Munro 2001), and is reported to co-localize with the late Golgi marker mRFP-TlgB (Buhler et al. 2015).

\section{AN ORGANELLE IN DYNAMIC EQUILIBRIUM}

Various observations have suggested that the Golgi apparatus is a dynamic organelle with self-organizing properties, maintained in a dynamic state by continuous input of energy (Jackson 2009). Various lines of evidence indicate that this is also true in A. nidulans.

Both early and late $A$. nidulans Golgi compartments are transient (Pantazopoulou and Peñalva unpubl and Pantazopoulou et al. 2014). Late Golgi cisternae have an average lifetime of approximately 2 min (Pantazopoulou et al. 2014). That Golgi cisternae are transient is consistent with the cisternal maturation model. The fact that a fraction of cisternae are labeled by both early and late Golgi markers, as visualized in yeast (Losev et al. 2006, Matsuura-Tokita et al. 2006), also is consistent with Golgi maturation. Work to be reported elsewhere also has revealed that indeed early Golgi matures to late Golgi in A. nidulans (Pantazopoulou and Peñalva unpubl).

We have observed that early Golgi cisternae localize close to the apex (similar to the ER and ER exit sites (Pantazopoulou and Penalva 2009, Markina-Inarrairaegui et al. 2013), while late Golgi cisternae seem to be excluded from a subapical region (FIG. 2A) whose dimensions correlate with growth speed. Rapid growth correlates with large area of exclusion (in the range of a few micrometers from the apex), while slow growth correlates with smaller area of exclusion. Why is there exclusion of late Golgi from the most apical region? Because cisternae are transient, we assume that they would be continuously replenished in the cell. Because the late Golgi matures from the early Golgi, we would expect its temporal distance from the ER exit sites to be larger than that of the early Golgi. This means that, if lifetime of early Golgi cisternae was approximately 2 min (we have measured late Golgi cisternae lifetime to be $2 \mathrm{~min}$ ), late Golgi would appear with more than a 2 min delay after assembly of the early Golgi. A 2 min delay would result in a $2 \mu \mathrm{m}$ distance from the apex of the most apical late Golgi cisternae (assembled by input from the apical ER exit sites), in hyphae growing at a routine speed of $1 \mu \mathrm{m} / \mathrm{min}$ (if there was no transport of late Golgi toward the apex) and this in fact is consistent with the distance we have observed. It would be remarkable if the apical late Golgi exclusion zone reflected maturation. However, other factors, such as different cytoskeleton attachment attributes of the late Golgi in comparison 
to the early Golgi, may be responsible for these observations.

Although excluded from the most apical tip region, the late Golgi has a remarkably polarized distribution toward the growing tip that is more pronounced than the polarization displayed by the early Golgi or the ER exit sites markers (Pantazopoulou and Penalva 2009). This suggests that the dynamics of membrane traffic pathways involving the Golgi at the crossroads of endocytosis and exocytosis might reach a different equilibrium at the tip. For example, the late Golgi at the tip might enrich its membranes accepting largescale recycling traffic from the adjacent subapical endocytic ring.

In agreement with cisternae being transient, blocking the ER exit, by shifting to the restrictive temperature a strain carrying a mutant $\operatorname{sarA}^{\text {sarl }}$ allele that causes thermosensitivity, resulted in early Golgi markers (SedV, RerA) re-localizing to the ER (Hernandez-Gonzalez et al. 2015). Block in Golgi assembly by conditional mutants of the essential early Golgi regulators RabO and SedV resulted in early Golgi markers relocalizing to a haze (Pinar et al. 2013). Interfering with the ER-Golgi interface in all three conditional mutants results in late Golgi disorganization with $\mathrm{PH}^{\mathrm{OSBP}}$ becoming cytoplasmic and $\mathrm{TlgB}$ redistributing to faintly labeled structures, possibly Golgi remnants (Pinar et al. 2013, Hernandez-Gonzalez et al. 2015). Rapid disorganization of the late Golgi as a consequence of a block at the early Golgi assembly is consistent with the late Golgi originating from the early Golgi by maturation.

After treatment with BFA, the A. nidulans Golgi collapses into large aggregates in fewer than 5 min. This behavior is characteristic of the Golgi in that neither the ER, labelled by the translocon component Sec63-GFP, or the ER exit sites, labelled by the COPII component Sec23-GFP, apparently respond to BFA addition (Pantazopoulou and Penalva 2009, MarkinaInarrairaegui et al. 2013). In mammalian cells, in the presence of BFA, the TGN mixes with recycling endosomes, a marker of which is Rab11 (Sonnichsen et al. 2000) while Golgi is reabsorbed by the ER (LippincottSchwartz et al. 1991). By analogy, prolonged ( $>5-10$ min and $<30-45 \mathrm{~min}$ ) BFA treatment in A. nidulans results in early Golgi marker SedV redistributing to the ER, while the late Golgi, which matures to $\mathrm{RabE}^{\mathrm{RAB} 11}$-containing post-Golgi carriers in untreated cells (Pantazopoulou et al. 2014), remains ER-independent (Pantazopoulou and Penalva 2011 and unpubl obs). BFA also leads to a transient apical extension arrest (Pantazopoulou and Penalva 2009). A. nidulans hyphae recover spontaneously from BFA treatment ( $>45 \mathrm{~min}$ to $1 \mathrm{~h}$ ), resuming growth as the Golgi apparatus reorganizes. The role that Golgi BFA aggregates may have in the reorganization of the Golgi structure during the recovery is unknown.

Although dynamic the $A$. nidulans Golgi complex does not undergo fragmentation during mitosis (Pantazopoulou and Penalva 2009) (A. nidulans mitosis is closed, meaning that the nuclear membrane is not disassembled, although nuclear pore complexes are [De Souza et al. 2004]), unlike what is seen in mammalian cells. In that respect Golgi of filamentous fungi is similar to yeast Golgi.

\section{RABC $^{\text {RaB6 }}$ AND ACTIN FILAMENTS CONTRIBUTE TO GOLGI ARCHITECTURE AND DYNAMICS}

Yeast Ypt6 (human Rab6) is a Golgi-associated Rab GTPase implicated in several Golgi-related retrograde pathways. For example, Ypt6 interacts with subunits of the GARP tethering complex, acting on retrograde transport from the endosomes to the late Golgi (Siniossoglou and Pelham 2001, Bonifacino and Hierro 2011); Rab6 effectors interact with the retromer coat complex implicated in protein recycling from the endosomes to the Golgi (Wassmer et al. 2009); COG8, a nonessential subunit of the intraGolgi-transport-mediating multisubunit tether COG, becomes essential in the absence of Ypt6 (Whyte and Munro 2001); Rab6 also is implicated in CopI-dependent and independent retrograde intra-Golgi and Golgi-to-ER pathways (Girod et al. 1999, Smith et al. 2009, Storrie et al. 2012). Many golgins (proteins that influence Golgi organization) are known effectors of Rab6 (Ramirez and Lowe 2009). In A. nidulans RabC $^{\text {Rab6 }}$ localizes at the Golgi (Pantazopoulou and Penalva 2011). Subunits of the COG complex also localize at the Golgi and have an impact on polarized growth and protein glycosylation (Gremillion et al. 2014). A. nidulans rabC $\Delta$ mutant is viable, even though it has major growth defects, both in hyphal morphology and growth rate (Pantazopoulou and Penalva 2011, Penalva et al. 2012). We have shown that $r a b C \Delta$ growth defect correlates with severely altered Golgi architecture. Both late $\mathrm{PH}^{\mathrm{OSBP}}$ - and early SedV-labeled cisternae in $r a b C \Delta$ are much smaller and more numerous than in the wild type, suggesting that cisternae are fragmented (Pantazopoulou and Penalva 2011). The Golgi apparatus also is severely depolarized. The late Golgi apex-proximal exclusion zone (see above and FIG. 2A) is largely lost. Moreover, BFA treatment of $\mathrm{rabC \Delta}$ cells does not result in collapse of the Golgi into BFAaggregates, suggesting that this collapse is RabC-dependent. Although these observations established an important role of RabC in Golgi architecture and dynamics, the mechanistic basis of this role is not understood. rabC $\Delta$ growth defect also correlates with a more prominent SPZ, probably linked to altered secretory carriers' 
fusogenicity (Pantazopoulou and Penalva 2011, Penalva et al. 2012). Identification and study of RabC effectors in the future may be instrumental in understanding the multiple roles that RabC exerts on secretion.

Golgi architecture also depends on F-actin in $A$. nidulans, because F-actin depolymerization by Latrunculin B resulted in late Golgi cisternae fragmentation and depolarization and loss of the late Golgi subapical exclusion zone, an effect that overall is similar to the effect $r a b C \Delta$ has on the Golgi (Pantazopoulou and Penalva 2009).

\section{UNLOCKING GOLGI EXIT}

The Golgi maturation model for cargo transport predicts that Golgi cisternae eventually dissipate into secretory carriers and carriers bound to the endosomal system.

RabE ${ }^{R A B 11}$ and its Guanine nucleotide exchange factor (GEF), TRAPPII.-In yeast three Rab GTPases regulate exocytosis, the Ypt31/Ypt32 paralogs (and Rab11 homologs), and Sec4, a homolog of Rab8. Ypt31/32, is involved in Golgi exit and collaborates with PI4P at late secretory compartments to recruit myosin $\mathrm{V}$ for polarized transport of secretory carriers (Jedd et al. 1997, Lipatova et al. 2008, Jin et al. 2011, Santiago-Tirado et al. 2011). Myosin $\mathrm{V}$ contributes to secretion in $U$. maydis and A. nidulans (Zhang et al. 2011, Schuster et al. 2012, Taheri-Talesh et al. 2012). Yeast Sec4 acts downstream of Ypt31/32 (Jedd et al. 1997, Ortiz et al. 2002). Unlike in yeast Sec 4 homologs are not essential in A. niger (Punt et al. 2001), A. fumigatus (PowersFletcher et al. 2013) or A. nidulans (Pantazopoulou et al. 2014), but the only A. nidulans Ypt31/Ypt32 homolog, RabE, is essential (Pantazopoulou et al. 2014). A. nidulans GFP-Sec4 co-localizes at the SPZ with GFP-RabE, but GFP-RabE additionally localizes at rapidly moving structures and Golgi-like elements (Pantazopoulou et al. 2014). By co-filming GFP-RabE with the late Golgi marker mRFP-PH ${ }^{\mathrm{OSBP}}$, we found that late Golgi cisternae are transient and that, at the final stage of their life cycle, which is marked by a gradual drop in $\mathrm{PH}^{\mathrm{OSBP}}$, they recruit GFP-RabE. Thus $\mathrm{PH}^{\mathrm{OSBP}}$ and $\mathrm{RabE}$ co-localize at late cisternae for approximately $25 \mathrm{~s}$. After this period $\mathrm{PH}^{\mathrm{OSBP}}$ drops below the detection limit, which is also true for Sec7GFP, and this coincides with acquirement of longrange motility by GFP-RabE-containing membranes. Thus $\mathrm{PH}^{\mathrm{OSBP}}$ subsidence coincides with Golgi exit, demarcating the passage from the Golgi apparatus to post-Golgi carriers. GFP-RabE carriers that are loaded with myosin $\mathrm{V}$, one or more kinesins and dynein and whose motility depends on both actin and microtubules, have been observed in high temporal resolution movies to bombard the SPZ (Pantazopoulou et al. 2014). Motile GFP-RabE carriers are clearly distinct from the similarly motile RabA ${ }^{\text {Rab5 }}$ early endosomes (Abenza et al. 2009, Pantazopoulou et al. 2014).

But what exactly regulates this transformation at the edge of the Golgi territory? GFP-RabE accumulation at the SPZ depends on BFA for in its presence GFP-RabE becomes cytoplasmic, which suggests that as expected membrane recruitment of RabE depends on functional Golgi. BFA has predictably two targets at the A. nidulans Golgi: the two Golgi Arf1 GEFs, that is GeaA, homolog of the early Golgi GBF1/Gealp and $\mathrm{HypB}^{\mathrm{Sec} 7}$, homolog of the late Golgi BIG/Sec7p. However, although shifting the conditional late Golgi hypB $5^{\text {sec } 7 t s}$ mutant (Yang et al. 2008, Arst et al. 2014) to the restrictive temperature resulted in GFP-RabE relocalizing from the SPZ to abnormal membrane aggregations in the proximity of the nucleus, it did not mimic the dispersion to the cytoplasm elicited by BFA. This suggests that RabE recruitment to membranes depends on a determinant acting upstream of (or independent of) $\mathrm{HypB}^{\mathrm{Sec} 7}$ and downstream of the early BFA target, the Golgi Arf1-GEF GeaA.

hypA1 is another thermosensitive mutant of the $h y p$ collection, found to control hyphal morphogenesis through secretion (Kaminskyj and Hamer 1998, Harris et al. 1999, Shi et al. 2004). HypA is a homolog of Trs120, a subunit of the Golgi-related oligomeric transport protein particle (TRAPP) complex. TRAPP comes in two versions, TRAPPI and TRAPPII, the latter deriving from the former by acquisition of three TRAPPIIspecific subunits, Trs120, Trs130 and Trs65 (Sacher et al. 2008). TRAPPI is a demonstrated GEF of Ypt1/ Rab1 (GEFs stimulate GDP release to allow binding of GTP by GTPases and determine Rab GTPases membrane recruitment and the subsequent recruitment of Rab effectors). The physiological role of TRAPPII was controversial: Some data pointed at TRAPPII being the GEF of Ypt31, which suggested that conversion of TRAPPI into TRAPPII at the Golgi would result in a transition from an earlier, Ypt1-containing, to a later, Ypt31-containing, compartment (Sacher et al. 2008). However, other studies have showed that in vitro both TRAPPI and II are Ypt1 GEFs (Cai et al. 2008), suggesting that one version of TRAPP might activate Ypt1 at the early Golgi, while the other might activate Ypt1 at the late Golgi. Using genetic, biochemical and microscopy tools, as well as the emerging power of $A$. nidulans cell biology comprehension, this major controversy in the field of Golgi biology was settled with help from hyphal cells. HypA ${ }^{\text {Trs120 }}$ is essential. Shifting hypA1 cells to the restrictive temperature relocalizes RabE from SPZ-associated membranes to the 
cytoplasm (like BFA), while it does not affect $\mathrm{RabO}^{\mathrm{Ypt1}}$ localization, consistent with hypA1 inactivating a RabEspecific GEF (Pinar et al. 2015). A laborious effort to recover extragenic suppressors of hypA1 yielded a collection of RabE mutants, of which several were shown to accelerate RabE GDP release (Pinar et al. 2015). These mutants rescued the null hypA $\Delta$ mutant, and remarkably they also rescued $h y p C \Delta$, the null mutant of the gene coding for Trs130, another essential TRAPPII-specific subunit. These mutants on the other hand did not rescue a null mutant of a TRAPP core subunit (i.e. common for TRAPPI and TRAPPII) or the null rabOD mutant, suggesting that they specifically bypass TRAPPII. TRAPPII subunits were further shown to associate with RabE in vivo but not with RabO. In vitro TRAPPII exhibited GEF activity on both RabO and RabE, suggesting that TRAPPI activity is retained in TRAPPII, perhaps because the formation of a RabEspecific binding site in TRAPPII does not perturb the RabO binding site on TRAPP (Pinar et al. 2015). TRAPPII-specific Trs120-GFP colocalizes with RabE at the late Golgi but, contrary to RabE, is largely released before carriers arrive at the SPZ, consistent with TRAPPII acting upstream of RabE at the late-Golgi to postGolgi transition (Pinar et al. 2015).

It is plausible that recruitment of TRAPPII to the late Golgi is independent of $\mathrm{HypB}^{\mathrm{Sec} 7}$ and this is why RabE remains associated with membranes in the hypB5 mutant. However, it is expected that hypB5 would affect the exit from the Golgi toward the endosomal system, in that all known adaptors of cargo destined to the endosomes are effectors of Arfl at the late Golgi, with $\mathrm{HypB}^{\mathrm{Sec} 7}$ being the late Golgi Arf1 GEF. Shifting hypB5 at the restricting temperature consistently blocks the apex-wise motility of RabE carriers with RabE membranes accumulating intracellularly. At those accumulations RabE membranes are abnormally associated with $\mathrm{RabA}^{\mathrm{Rab5}}$ membranes $\left(\mathrm{RabA}^{\mathrm{Rab5}}\right.$ is a marker of early endosomes [Abenza et al. 2009]) (Pantazopoulou et al. 2014), perhaps because $\mathrm{HypB}^{\text {Sec7 }}$ perturbation impedes cargo sorting at the late Golgi/ TGN, that would result in unresolved compartments of mixed endosomal/secretory identity.

The Arf1 Golgi GEFs, GeaA and HypB $B^{\text {Sec7 }}$.- The fact that treatment with BFA (predictably blocking GeaA and HypB, as explained above) redistributes RabE from membranes to the cytoplasm, while hypB5 shift at the restrictive temperature does not impede RabE membrane association, would suggest that it is the early Golgi Arfl GEF, GeaA, that is indispensable for RabE membrane association. This is perhaps because GeaA has a more central role on Golgi integrity than $\mathrm{HypB}^{\mathrm{Sec} 7}$ that might play a more specific role on Golgi exit used by specialized cargoes.
The roles that two distinct, universally conserved in eukaryotes, Golgi GEFs for Arf1 play are not clear (Mouratou et al. 2005). Each Arfl GEF is present either at the early or late Golgi. It has been suggested that these large $(\approx 1500-2000$ aa $)$, multidomain proteins themselves can contact specific protein interactors, modifying the outcome of Arfl activation at each Golgi subcompartment. Yeast late Golgi Sec7, for example, has been shown to regulate and/or integrate feedbacks from multiple master Golgi regulators (Arl1, Arf1, Ypt1, Ypt31/32), resulting in coordination of Golgi functions, especially of Golgi entry and exit (McDonold and Fromme 2014). Yeast early Golgi Gealp has been shown to interact with a subunit of CopI (Deng et al. 2009), an Arf1 effector that has roles in intra-Golgi and Golgi-to-ER traffic. Apart from their largely unexplored roles, the specific membrane recruitment mechanism of Golgi Arf1 GEFs (they are peripheral membrane proteins) to specialized Golgi subcompartments is not understood (Wright et al. 2014).

Both Arf1-GEFs in A. nidulans, $\mathrm{HypB}^{\mathrm{Sec} 7}$ and GeaA, are virtually essential (Arst et al. 2014). Using genetics once again, extragenic suppressors of the conditional late Golgi Arfl GEF mutant hypB5 were sought (Arst et al. 2014). Among lots of intragenic suppressors, we recovered a single extragenic one that carries a mutation in the early Golgi Arfl GEF, GeaA. The geaA1 mutant allele rescued $h y p B \Delta$. In silico analysis of the similarity of proteins in the GBF/GeaA and BIG/ Sec7 subfamilies, showed that the amino acid substitution in GeaA1 lies in a GBF/Gea-specific (not found in BIG/Sec7) tripeptide motif. Remarkably the suppressor mutation substantially shifted the localization of GeaA1-GFP from the early Golgi to the apical plasma membrane and to a SPZ-resembling accumulation beneath it (Arst et al. 2014). The mechanism by which GeaA1 bypasses $\mathrm{HypB}^{\mathrm{Sec} 7}$ essential functions remains unexplored. However, toleration of such a break in Golgi Arf1 GEFs asymmetry was unprecedented in eukaryotes. Answering how Golgi subcompartments lacking a master late Golgi regulator are maintained and maintain filamentous fungal growth most probably would provide new insights on Golgi function in the future.

\section{ACKNOWLEDGMENTS}

I thank Miguel Peñalva for constructive discussions and for critically reading the manuscript. I thank Richard Howard, Michelle Momany and Jaclyn Dee (and of course their collaborators) for kindly letting me use their electron microscopy data. This work was supported by Ministerio de Economía y Competitividad (Spain) Grant BIO2012-30965 and Comunidad de Madrid Grant S2010/BMD-2414 to Miguel Peñalva. 


\section{LITERATURE CITED}

Abeliovich H, Grote E, Novick P, Ferro-Novick S. 1998. Tlg2p, a yeast syntaxin homolog that resides on the Golgi and endocytic structures. J Biol Chem 273: 11719-11727, doi:10.1074/jbc.273.19.11719

Abenza JF, Pantazopoulou A, Rodriguez JM, Galindo A, Penalva MA. 2009. Long-distance movement of Aspergillus nidulans early endosomes on microtubule tracks. Traffic 10:57-75, doi:10.1111/j.1600-0854.2008.00848.x

Akao T, Yamaguchi M, Yahara A, Yoshiuchi K, Fujita H, Yamada O, Akita O, Ohmachi T, Asada Y, Yoshida T. 2006. Cloning and expression of 1,2-alpha-mannosidase gene (fmanIB) from filamentous fungus Aspergillus oryzae: in vivo visualization of the FmanIBp-GFP fusion protein. Biosci, Biotechnol Biochem 70:471-479, doi:10. $1271 /$ bbb. 70.471

Amessou M, Fradagrada A, Falguieres T, Lord JM, Smith DC, Roberts LM, Lamaze C, Johannes L. 2007. Syntaxin 16 and syntaxin 5 are required for efficient retrograde transport of several exogenous and endogenous cargo proteins. J Cell Sci 120:1457-1468, doi:10.1242/jcs. 03436

Archer DB. 2000. Filamentous fungi as microbial cell factories for food use. Curr Op Biotechnol 11:478-483, doi:10.1016/S0958-1669(00)00129-4

Arst HN Jr, Hernandez-Gonzalez M, Penalva MA, Pantazopoulou A. 2014. GBF/Gea mutant with a single substitution sustains fungal growth in the absence of BIG/Sec7. FEBS Lett 588:4799-4806, doi:10.1016/j. febslet.2014.11.014

Barr FA. 2013. Review series: Rab GTPases and membrane identity: causal or inconsequential? J Cell Biol 202: 191-199, doi:10.1242/jcs.02810

Behnia R, Barr FA, Flanagan JJ, Barlowe C, Munro S. 2007. The yeast ortholog of GRASP65 forms a complex with a coiled-coil protein that contributes to ER to Golgi traffic. J Cell Biol 176:255-261, doi:10.1093/embo-reports/ kve065

Beznoussenko GV, Dolgikh VV, Seliverstova EV, Semenov PB, Tokarev YS, Trucco A, Micaroni M, Di Giandomenico D, Auinger P., Senderskiy IV, et al. 2007. Analogs of the Golgi complex in microsporidia: structure and avesicular mechanisms of function. J Cell Sci 120: 1288-1298, doi:10.1242/jcs.03402

Billen J, Morgan ED. 1998. Pheromone communication in social insects: sources and secretions. In: vander Meer, ed. Pheromone communication in social insects: ants, wasps, bees and termites. Boulder, Colorado: Westview Press. p 3-33.

Bolte S, Cordelieres FP. 2006. A guided tour into subcellular colocalization analysis in light microscopy. J Microscopy 224:213-232, doi:10.1111/j.1365-2818.2006.01706.x

Bonifacino JS, Hierro A. 2011. Transport according to GARP: receiving retrograde cargo at the trans-Golgi network. Trends Cell Biol 21:159-167, doi:10.1016/j.tcb. 2010.11.003

Bourett TM, James SW, Howard RJ. 2007. The endomembrane system of the fungal cell. In: Howard R, Gow
NR, eds. Biology of the fungal cell. Berlin: Springer. p 1-47.

Bowman BJ, Draskovic M, Freitag M, Bowman EJ. 2009. Structure and distribution of organelles and cellular location of calcium transporters in Neurospora crassa. Euk Cell 8:1845-1855, doi:10.1128/EC.00174-09

Breakspear A, Langford KJ, Momany M, Assinder SJ. 2007. CopA:GFP localizes to putative Golgi equivalents in Aspergillus nidulans. FEMS Microbiol Lett 277:90-97, doi:10.1111/j.1574-6968.2007.00945.x

Brigance WT, Barlowe C, Graham TR. 2000. Organization of the yeast golgi complex into at least four funtionally distinct compartments. Mol Biol Cell 11:171-182, doi:10.1091/mbc.11.1.171

Buhler N, Hagiwara D, Takeshita N. 2015. Functional analysis of sterol transporter orthologs in the filamentous fungus Aspergillus nidulans. Euk Cell 14:908-921, doi:10.1128/ EC.00027-15

Cai Y, Chin HF, Lazarova D, Menon S, Fu C, Cai H, Sclafani A, Rodgers DW, de la Cruz EM, Ferro-Novick S, et al. 2008. The structural basis for activation of the Rab Yptlp by the TRAPP membrane-tethering complexes. Cell 133:1202-1213, doi:10.1016/j.cell.2008.04.049

Casanova JE, Hsu VW, Jackson CL, Kahn RA, Roy CR, Stow JL, Wandinger-Ness A, Sztul E. 2013. Meeting report-Arf and Rab family G proteins. J Cell Sci 126: 5313-5316, doi:10.1242/jcs.143610

Chappell TG, Hajibagheri MA, Ayscough K, Pierce M, Warren G. 1994. Localization of an alpha 1,2 galactosyltransferase activity to the Golgi apparatus of Schizosaccharomyces pombe. Mol Biol Cell 5:519-528, doi:10.1091/mbc.5.5.519

Colanzi A, Corda D. 2007. Mitosis controls the Golgi and the Golgi controls mitosis. Curr Op Cell Biol 19:386-393, doi:10.1016/j.ceb.2007.06.002

Conesa A, Punt PJ, van Luijk N, van den Hondel CA. 2001. The secretion pathway in filamentous fungi: a biotechnological view. Fungal Genet Biol 33:155-171, doi:10.1006/fgbi.2001.1276

Daboussi L, Costaguta G, Payne GS. 2012. Phosphoinositidemediated clathrin adaptor progression at the transGolgi network. Nat Cell Biol 14:239-248, doi:10.1038/ ncb2427

Day KJ, Staehelin LA, Glick BS. 2013. A three-stage model of Golgi structure and function. Histochem Cell Biol 140:239-249, doi:10.1007/s00418-013-1128-3

de Matteis MA, Luini A. 2008. Exiting the Golgi complex. Nat Rev Mol Cell Biol 9:273-284, doi:10.1038/nrm2378

— Wilson C, D'Angelo G. 2013. Phosphatidylinositol4-phosphate: the Golgi and beyond. BioEssays 35: 612-622, doi:10.1002/bies.201200180

de Saint-Jean M, Delfosse V, Douguet D, Chicanne G, Payrastre B, Bourguet W, Antonny B, Drin G. 2011. Osh4p exchanges sterols for phosphatidylinositol 4phosphate between lipid bilayers. J Cell Biol 195: 965-978, doi:10.1126/science.1152066

de Souza CP, Osmani AH, Hashmi SB, Osmani SA. 2004. Partial nuclear pore complex disassembly during closed mitosis in Aspergillus nidulans. Curr Biol 14:1973-1984, doi:10.1016/j.cub.2004.10.050 
Dee JM, Mollicone M, Longcore JE, Roberson RW, Berbee ML. 2015. Cytology and molecular phylogenetics of Monoblepharidomycetes provide evidence for multiple independent origins of the hyphal habit in the Fungi. Mycologia 107:710-728, doi:10.3852/14-275

Deng Y, Golinelli-Cohen MP, Smirnova E, Jackson CL. 2009. A COPI coat subunit interacts directly with an early-Golgi localized Arf exchange factor. EMBO Rep 10:58-64, doi:10.1038/embor.2008.221

Donaldson JG, Jackson CL. 2011. ARF family G proteins and their regulators: roles in membrane transport, development and disease. Mol Cell Biol 12:362-375.

D'Souza-Schorey C, Chavrier P. 2006. ARF proteins: roles in membrane traffic and beyond. Nat Rev Mol Cell Biol 7:347-358.

Egan MJ, McClintock MA, Reck-Peterson SL. 2012. Microtubule-based transport in filamentous fungi. Curr Op Microbiol 15:637-645, doi:10.1016/j.mib.2012. 10.003

Emr S, Glick BS, Linstedt AD, Lippincott-Schwartz J, Luini A, Malhotra V, Marsh BJ, Nakano A, Pfeffer SR, Rabouille C et al. 2009. Journeys through the Golgi-taking stock in a new era. J Cell Biol 187:449-453, doi:10.1016/ S0092-8674(00) 81548-2

Farquhar MG. 1985. Progress in unraveling pathways of Golgi traffic. Ann Rev Cell Biol 1:447-488, doi:10.1146/ annurev.cb.01.110185.002311

Gillingham AK, Munro S. 2007. The small G proteins of the Arf family and their regulators. Ann Rev Cell Develop Biol 23:579-611, doi:10.1146/annurev.cellbio. 23.090506.123209

Girbardt M. 1969. Die Ultrastruktur der Apikalregion von Pilzhyphen. Protoplasma 67:413-441, doi:10.1007/ BF01254905

Girod A, Storrie B, Simpson JC, Johannes L, Goud B, Roberts LM, Lord JM, Nilsson T, Pepperkok R. 1999. Evidence for a COP-I-independent transport route from the Golgi complex to the endoplasmic reticulum. Nat Cell Biol 1:423-430, doi:10.1038/15658

Glick BS. 1996. Cell biology: alternatives to baker's yeast. Curr Biol 6:1570-1572, doi:10.1016/S0960-9822(02) 70774-4

— Luini A. 2011. Models for Golgi traffic: a critical assessment. Cold Spring Harbor Perspectives Biol 3: a005215.

Gould SJ, McCollum D, Spong AP, Heyman JA, Subramani S. 1992. Development of the yeast Pichia pastoris as a model organism for a genetic and molecular analysis of peroxisome assembly. Yeast 8:613-628, doi:10.1002/ yea.320080805

Graham TR, Emr SD. 1991. Compartmental organization of Golgi-specific protein modification and vacuolar protein sorting events defined in a yeast sec18 (NSF) mutant. J Cell Biol 114:207-218, doi:10.1083/jcb.114.2.207

Gremillion SK, Harris SD, Jackson-Hayes L, Kaminskyj SG, Loprete DM, Gauthier AC, Mercer S, Ravita AJ, Hill TW. 2014. Mutations in proteins of the Conserved Oligomeric Golgi Complex affect polarity, cell wall structure and glycosylation in the filamentous fungus
Aspergillus nidulans. Fungal Genet Biol 73:69-82, doi:10.1016/j.fgb.2014.10.005

Grove SN, Bracker CE. 1970. Protoplasmic organization of hyphal tips among fungi: vesicles and Spitzenkorper. J Bacteriol 104:989-1009.

Guo Y, Sirkis DW, Schekman R. 2014. Protein sorting at the trans-Golgi network. Ann Rev Cell Develop Biol 30:169-206, doi:10.1146/annurev-cellbio-100913013012

Hankins HM, Baldridge RD, Xu P, Graham TR. 2015a. Role of flippases, scramblases and transfer proteins in phosphatidylserine subcellular distribution. Traffic 16: 35-47, doi:10.1111/tra.12233

- Sere YY, Diab NS, Menon AK, Graham TR. 2015b. Phosphatidylserine translocation at the yeast trans-Golgi network regulates protein sorting into exocytic vesicles. Mol Biol Cell 26:4674-4685, doi:10.1091/mbc.E1507-0487

Harris SD. 2013. Golgi organization and the apical extension of fungal hyphae: an essential relationship. Mol Microbiol 89:212-215, doi:10.1111/mmi.12291

_ , Hofmann AF, Tedford HW, Lee MP. 1999. Identification and characterization of genes required for hyphal morphogenesis in the filamentous fungus Aspergillus nidulans. Genetics 151:1015-1025.

Hernandez-Gonzalez M, Penalva MA, Pantazopoulou A. 2015. Conditional inactivation of Aspergillus nidulans sarA(SAR1) uncovers the morphogenetic potential of regulating endoplasmic reticulum (ER) exit. Mol Microbiol 95:491-508, doi:10.1111/mmi.12880

Herrero-Garcia E, Perez-de-Nanclares-Arregi E, Cortese MS, Markina-Inarrairaegui A, Oiartzabal-Arano E, Etxebeste O, Ugalde U, Espeso EA. 2015. Tip-to-nucleus migration dynamics of the asexual development regulator FlbB in vegetative cells. Molecular microbiology 98:607-624, doi:10.1111/mmi.13156

Hoang HD, Maruyama J, Kitamoto K. 2015. Modulating endoplasmic reticulum-Golgi cargo receptors for improving secretion of carrier-fused heterologous proteins in the filamentous fungus Aspergillus oryzae. Applies and environmental microbiology 81:533-543, doi:10.1128/AEM.02133-14

Hoch HC, Howard RJ. 1980. Ultrastructure of freezesubstituted hyphae of the basidiomyceteLaetisaria arvalis. Protoplasma 103:281-297, doi:10.1128/AEM. 02133-14

Holthuis JC, Menon AK. 2014. Lipid landscapes and pipelines in membrane homeostasis. Nature 510:48-57, doi:10.1038/nature 13474

Howard RJ. 1981. Ultrastructural analysis of hyphal tip cell growth in fungi: Spitzenkorper, cytoskeleton and endomembranes after freeze substitution. J Cell Sci 48:89-103.

Hubbard MA, Kaminskyj SG. 2008. Rapid tip-directed movement of Golgi equivalents in growing Aspergillus nidulans hyphae suggests a mechanism for delivery of growth-related materials. Microbiology 154:1544-1553, doi:10.1099/mic.0.2007/014811-0 
Jackson CL. 2009. Mechanisms of transport through the Golgi complex. J Cell Sci 122:443-452, doi:10.1242/ jcs.032581

Jackson-Hayes L, Hill TW, Loprete DM, Fay LM, Gordon BS, Nkashama SA, Patel RK, Sartain CV. 2008. Two GDPmannose transporters contribute to hyphal form and cell wall integrity in Aspergillus nidulans. Microbiology 154:2037-2047, doi:10.1099/mic.0.2008/017483-0

$\longrightarrow,-$ - $\longrightarrow$, Gordon BS, Groover CJ, Johnson LR, Martin SA. 2010. GDP-mannose transporter paralogues play distinct roles in polarized growth of Aspergillus nidulans. Mycologia 102:305-310, doi:10.3852/09-138

Jedd G, Mulholland J, Segev N. 1997. Two new Ypt GTPases are required for exit from the yeast trans-Golgi compartment. J Cell Biol 137:563-580, doi:10.1016/0955-0674 (93)90130-I

Jékely G. 2008. Evolution of the Golgi complex. In: Mironov A, Pavelka M, eds. The Golgi apparatus,. Vienna, Austria: Springer. p 675-691.

Jin Y, Sultana A, Gandhi P, Franklin E, Hamamoto S, Khan AR, Munson M, Schekman R, Weisman LS. 2011. Myosin V transports secretory vesicles via a Rab GTPase cascade and interaction with the exocyst complex. Develop Cell 21:1156-1170, doi:10.1016/j.devcel.2011. 10.009

Kajiwara K, Ikeda A, Aguilera-Romero A, Castillon GA, Kagiwada S, Hanada K, Riezman H, Muniz M, Funato K. 2014. Osh proteins regulate COPII-mediated vesicular transport of ceramide from the endoplasmic reticulum in budding yeast. J Cell Sci 127:376-387, doi:10.1242/jcs.132001

Kaminskyj SG, Hamer JE. 1998. hyp loci control cell pattern formation in the vegetative mycelium of Aspergillus nidulans. Genetics 148:669-680.

Kohli M, Galati V, Boudier K, Roberson RW, Philippsen P. 2008. Growth-speed-correlated localization of exocyst and polarisome components in growth zones of Ashbya gossypii hyphal tips. Journal of cell science 121:3878-3889, doi: $10.1242 /$ jcs.033852

Kuratsu M, Taura A, Shoji JY, Kikuchi S, Arioka M, Kitamoto K. 2007. Systematic analysis of SNARE localization in the filamentous fungus Aspergillus oryzae. Fungal Genet Biol 44:1310-1323, doi:10.1016/j.fgb.2007.04.012

Lee I, Tiwari N, Dunlop MH, Graham M, Liu X, Rothman JE. 2014. Membrane adhesion dictates Golgi stacking and cisternal morphology. Proc Natl Acad Sci USA 111:1849-1854, doi:10.1073/pnas.1323895111

Lee SC, Shaw BD. 2008. Localization and function of ADP ribosylation factor A in Aspergillus nidulans. FEMS Microbiol Lett 283:216-222, doi:10.1111/j.1574-6968. 2008.01174.x

Levine TP, Munro S. 2001. Dual targeting of Osh1p, a yeast homolog of oxysterol-binding protein, to both the Golgi and the nucleus-vacuole junction. Mol Biol Cell 12:1633-1644, doi:10.1091/mbc.12.6.1633

. 2002. Targeting of Golgi-specific pleckstrin homology domains involves both PtdIns 4-kinasedependent and -independent components. Curr Biol 12:695-704, doi:10.1016/S0960-9822(02)00779-0
Lewis MJ, Nichols BJ, Prescianotto-Baschong C, Riezman H, Pelham HR. 2000. Specific retrieval of the exocytic SNARE Snclp from early yeast endosomes. Mol Biol Cell 11:23-38, doi:10.1091/mbc.11.1.23

Li Q, Lau A, Morris TJ, Guo L, Fordyce CB, Stanley EF. 2004. A syntaxin 1, Galpha(o), and N-type calcium channel complex at a presynaptic nerve terminal: analysis by quantitative immunocolocalization. J Neurosci 24: 4070-4081, doi:10.1523/JNEUROSCI.0346-04.2004

Lipatova Z, Tokarev AA, Jin Y, Mulholland J, Weisman LS, Segev N. 2008. Direct interaction between a myosin $\mathrm{V}$ motor and the Rab GTPases Ypt31/32 is required for polarized secretion. Mol Biol Cell 19:4177-4187, doi:10.1091/mbc.E08-02-0220

Lippincott-Schwartz J, Yuan L, Tipper C, Amherdt M, Orci L, Klausner RD. 1991. Brefeldin A's effects on endosomes, lysosomes and the TGN suggest a general mechanism for regulating organelle structure and membrane traffic. Cell 67:601-616, doi:10.1016/0092-8674(91)90534-6 -, Yuan LC, Bonifacino JS, Klausner RD. 1989. Rapid redistribution of Golgi proteins into the ER in cells treated with brefeldin A: evidence for membrane cycling from Golgi to ER. Cell 56:801-813, doi:10.1016/00928674(89)90685-5

Liu S, Storrie B. 2012. Are Rab proteins the link between Golgi organization and membrane trafficking? Cell Mol Life Sci 69:4093-4106, doi:10.1007/s00018-0121021-6

López-Berges MS, Pinar M, Abenza JF, Arst HN, Peñalva MA. 2016. The Aspergillus nidulans syntaxin $\mathrm{PepA}^{\mathrm{Pep} 12}$ is regulated by two Sec1/Munc-18 proteins to mediate fusion events at early endosomes, late endosomes and vacuoles. Mol Microbiol 99:199-216.

Losev E, Reinke CA, Jellen J, Strongin DE, Bevis BJ, Glick BS. 2006. Golgi maturation visualized in living yeast. Nature 441:1002-1006, doi:10.1038/nature04717

Maeda K, Anand K, Chiapparino A, Kumar A, Poletto M, Kaksonen M, Gavin AC. 2013. Interactome map uncovers phosphatidylserine transport by oxysterolbinding proteins. Nature 501:257-261, doi:10.1038/ nature 12430

Markina-Inarrairaegui A, Pantazopoulou A, Espeso EA, Penalva MA. 2013. The Aspergillus nidulans peripheral ER: disorganization by ER stress and persistence during mitosis. PloS one 8:e67154.

Matsuura-Tokita K, Takeuchi M, Ichihara A, Mikuriya K, Nakano A. 2006. Live imaging of yeast Golgi cisternal maturation. Nature 441:1007-1010, doi:10.1371/journal. pone.0067154.s003

McDonold CM, Fromme JC. 2014. Four GTPases differentially regulate the Sec7 Arf-GEF to direct traffic at the trans-Golgi network. Develop Cell 30:759-767, doi:10. 1016/j.devcel.2014.07.016

McLaughlin DJ. 1974. Ultrastructural localization of carbohydrate in the hymenium and subhymenium of Coprinus. Evidence for the function of the Golgi apparatus. Protoplasma 82:341-364, doi:10.1007/BF01275728

Meer RV, Preston C. 2008. Social insect pheromones. In: Capinera J, ed. Encycl Entomol. The Netherlands: Springer. p 3440-3447. 
Meyer V, Fiedler M, Nitsche B, King R. 2015. The cell factory Aspergillus enters the big data era: opportunities and challenges for optimizing product formation. Advanc Biochem Engineer/Biotechnol 149:91-132.

Mims CW, Richardson EA, Timberlake WE. 1988. Ultrastructural analysis of conidiophore development in the fungus Aspergillus nidulans using freeze-substitution. Protoplasma 144:132-141, doi:10.1007/10_2014_297

Mironov A, Pavelka M. 2008a. The Golgi apparatus as a crossroads in intracellular traffic. In: Mironov A, Pavelka M, eds. The Golgi apparatus. Vienna, Austria: Springer. p 16-39.

- 2008b. The Golgi apparatus-state of the art 110 years after Camillo Golgi's discovery Vienna, Austria: Springer.

Mironov AA, Sesorova IV, Beznoussenko GV. 2013. Golgi's way: a long path toward the new paradigm of the intra-Golgi transport. Histochem Cell Biol 140: 383-393, doi:10.1007/s00418-013-1141-6

Momany M, Richardson EA, van Sickle C, Jedd G. 2002. Mapping Woronin body position in Aspergillus nidulans. Mycologia 94:260-266, doi:10.2307/3761802

Moser von Filseck J, Copic A, Delfosse V, Vanni S, Jackson CL, Bourguet W, Drin G. 2015. Intracellular transport: phosphatidylserine transport by ORP/Osh proteins is driven by phosphatidylinositol 4-phosphate. Science 349:432-436, doi:10.1126/science.aab1346

Mouratou B, Biou V, Joubert A, Cohen J, Shields DJ, Geldner N, Jurgens G, Melancon P, Cherfils J. 2005. The domain architecture of large guanine nucleotide exchange factors for the small GTP-binding protein Arf. BMC Genom 6:20.

Munro S. 2005. The Golgi apparatus: defining the identity of Golgi membranes. Curr Op Cell Biol 17:395-401, doi:10.1016/j.ceb.2005.06.013

- 2011a. The golgin coiled-coil proteins of the Golgi apparatus. Cold Spring Harbor Perspect Biol 3, doi: 10.1101/cshperspect.a005256

- 2011b. What is the Golgi apparatus, and why are we asking? BMC Biol 9:63, doi:10.1186/1741-7007-9-63

Noirot C, Quennedey A. 1974. Fine structure of insect epidermal glands. Ann Rev Entomol 19:61-80, doi:10. 1146/annurev.en.19.010174.000425

Ortiz D, Medkova M, Walch-Solimena C, Novick P. 2002. Ypt32 recruits the Sec4p guanine nucleotide exchange factor, Sec2p, to secretory vesicles: evidence for a Rab cascade in yeast. J Cell Biol 157:1005-1015, doi:10. $1007 / \mathrm{s} 004380050944$

Paczkowski JE, Richardson BC, Fromme JC. 2015. Cargo adaptors: structures illuminate mechanisms regulating vesicle biogenesis. Trends Cell Biol 25:408-416, doi:10. 1016/j.tcb.2015.02.005

Panatala R, Hennrich H, Holthuis JC. 2015. Inner workings and biological impact of phospholipid flippases. J Cell Sci 128:2021-2032, doi:10.1242/jcs.102715

Pantazopoulou A, Peñalva MA. 2011. Characterization of Aspergillus nidulans RabC/Rab6. Traffic 12:386-406, doi:10.1111/j.1600-0854.2011.01164.x.
— Diallinas G. 2007. Fungal nucleobase transporters. FEMS Microbiol Rev 31:657-675, doi:10. 1111/j.1600-0854.2011.01164.x

— Aspergillus nidulans Golgi during apical extension and mitosis. Mol Biol Cell 20:4335-4347, doi:10.1091/mbc. E09-03-0254

— late-Golgi cisternae into RabE(RAB11) exocytic postGolgi carriers visualized in vivo. Mol Biol Cell 25:24282443, doi:10.1091/mbc.E14-02-0710

Papanikou E, Glick BS. 2014. Golgi compartmentation and identity. Curr Op Cell Biol 29:74-81.

Patterson GH, Hirschberg K, Polishchuk RS, Gerlich D, Phair RD, Lippincott-Schwartz J. 2008. Transport through the Golgi apparatus by rapid partitioning within a two-phase membrane system. Cell 133:1055-1067, doi:10.1016/ j.cell.2008.04.044

Penalva MA. 2015. A lipid-managing program maintains a stout Spitzenkorper. Mol Microbiol 97:1-6, doi:10. 1111/mmi.13044

, Galindo A, Abenza JF, Pinar M, Calcagno-Pizarelli AM, Arst HN, Pantazopoulou A. 2012. Searching for gold beyond mitosis: Mining intracellular membrane traffic in Aspergillus nidulans. Cell Log 2:2-14, doi:10. $4161 / \mathrm{cl} .19304$

Pinar M, Arst HN Jr, Pantazopoulou A, Tagua VG, de Los Rios V, Rodriguez-Salarichs J, Diaz JF, Penalva MA. 2015. TRAPPII regulates exocytic Golgi exit by mediating nucleotide exchange on the Ypt31 ortholog RabERAB11. Proc Natl Acad Sci USA 112:4346-4351, doi:10.1073/pnas.1419168112

_, Pantazopoulou A, Arst HN Jr, Penalva MA. 2013. Acute inactivation of the Aspergillus nidulans Golgi membrane fusion machinery: correlation of apical extension arrest and tip swelling with cisternal disorganization. Mol Microbiol 89:228-248, doi:10.1111/mmi. 12280

Polishchuk RS, Mironov AA. 2004. Structural aspects of Golgi function. Cell Mol Life Sci 61:146-158, doi:10.1007/ s00018-003-3353-8

Popoff V, Adolf F, Brugger B, Wieland F. 2011. COPI budding within the Golgi stack. Cold Spring Harbor Perspect Biol 3:a005231, doi:10.1101/cshperspect.a005231

Powers-Fletcher MV, Feng X, Krishnan K, Askew DS. 2013. Deletion of the sec 4 homolog srgA from Aspergillus fumigatus is associated with an impaired stress response, attenuated virulence and phenotypic heterogeneity. PloS one 8:e66741.

Preuss D, Mulholland J, Franzusoff A, Segev N, Botstein D. 1992. Characterization of the Saccharomyces Golgi complex through the cell cycle by immunoelectron microscopy. Mol Biol Cell 3:789-803, doi:10.1371/journal. pone.0066741.s002

Punt PJ, Seiboth B, Weenink XO, van Zeijl C, Lenders M, Konetschny C, Ram AF, Montijn R, Kubicek CP, van den Hondel CA. 2001. Identification and characterization of a family of secretion-related small GTPase-encoding genes from the filamentous fungus Aspergillus niger. a putative SEC4 homolog is not essential for growth. 
Mol Microbiol 41:513-525, doi:10.1046/j.1365-2958. 2001.02541.x

Ramirez IB, Lowe M. 2009. Golgins and GRASPs: holding the Golgi together. Seminars Cell Develop Biol 20:770-779, doi:10.1016/j.semcdb.2009.03.011

Riquelme M. 2013. Tip growth in filamentous fungi: a road trip to the apex. Ann Rev Microbiol 67:587-609, doi:10.1146/annurev-micro-092412-155652

Robineau S, Chabre M, Antonny B. 2000. Binding site of brefeldin $\mathrm{A}$ at the interface between the small $\mathrm{G}$ protein ADP-ribosylation factor 1 (ARF1) and the nucleotideexchange factor Sec7 domain. Proc Natl Acad Sci USA 97:9913-9918, doi:10.1073/pnas.170290597

Rossanese OW, Soderholm J, Bevis BJ, Sears IB, O’Connor J, Williamson EK, Glick BS. 1999. Golgi structure correlates with transitional endoplasmic reticulum organization in Pichia pastoris and Saccharomyces cerevisiae. J Cell Biol 145:69-81, doi:10.1016/0378-1119(85)90120-9

Rothman JE. 1981. The Golgi apparatus: two organelles in tandem. Science 213:1212-1219, doi:10.1126/science. 7268428

Sacher M, Kim YG, Lavie A, Oh BH, Segev N. 2008. The TRAPP complex: insights into its architecture and function. Traffic 9:2032-2042, doi:10.1111/j.1600-0854. 2008.00833.x

Sanchez-Leon E, Bowman B, Seidel C, Fischer R, Novick P, Riquelme M. 2015. The Rab GTPase YPT-1 associates with Golgi cisternae and Spitzenkorper microvesicles in Neurospora crassa. Mol Microbiol 95:472-490, doi:10. $1111 / \mathrm{mmi} .12878$

Santiago-Tirado FH, Legesse-Miller A, Schott D, Bretscher A. 2011. PI4P and Rab inputs collaborate in myosin-Vdependent transport of secretory compartments in yeast. Develop Cell 20:47-59, doi:10.1016/j.devcel. 2010.11.006

Sato K, Sato M, Nakano A. 1997. Rerlp as common machinery for the endoplasmic reticulum localization of membrane proteins. Proc Natl Acad Sci USA 94:9693-9698, doi:10.1073/pnas.94.18.9693

Schmitz HP, Philippsen P. 2011. Evolution of multinucleated Ashbya gossypii hyphae from a budding yeast-like ancestor. Fungal Biol 115:557-568, doi:10.1016/j.funbio. 2011.02.015

Schneider CA, Rasband WS, Eliceiri KW. 2012. NIH Image to ImageJ: 25 years of image analysis. Nat Meth 9:671-675, doi:10.1038/nmeth.2089

Schultzhaus Z, Yan H, Shaw BD. 2015. Aspergillus nidulans flippase DnfA is cargo of the endocytic collar and plays complementary roles in growth and phosphatidylserine asymmetry with another flippase, DnfB. Mol Microbiol 97:18-32, doi:10.1111/mmi.13019

Schuster M, Treitschke S, Kilaru S, Molloy J, Harmer NJ, Steinberg G. 2012. Myosin-5, kinesin-1 and myosin-17 cooperate in secretion of fungal chitin synthase. EMBO J 31:214-227, doi:10.1038/emboj.2011.361

Shi X, Sha Y, Kaminskyj S. 2004. Aspergillus nidulans hypA regulates morphogenesis through the secretion pathway. Fungal Genet Biol 41:75-88, doi:10.1016/j.fgb.2003.09.004

Short B, Haas A, Barr FA. 2005. Golgins and GTPases, giving identity and structure to the Golgi apparatus. Biochim
Biophys acta 1744:383-395, doi:10.1016/j.bbamcr. 2005.02.001

Siniossoglou S, Pelham HR. 2001. An effector of Ypt6p binds the SNARE Tlglp and mediates selective fusion of vesicles with late Golgi membranes. EMBO J 20: 5991-5998, doi:10.1093/emboj/20.21.5991

Smith RD, Willett R, Kudlyk T, Pokrovskaya I, Paton AW, Paton JC, Lupashin VV. 2009. The COG complex, Rab6 and COPI define a novel Golgi retrograde trafficking pathway that is exploited by SubAB toxin. Traffic 10:1502-1517, doi:10.1111/j.1600-0854.2009.00965.x

Sonnichsen B, de Renzis S, Nielsen E, Rietdorf J, Zerial M. 2000. Distinct membrane domains on endosomes in the recycling pathway visualized by multicolor imaging of Rab4, Rab5 and Rab11. J Cell Biol 149:901-914, doi:10.1083/jcb.140.5.1039

Storrie B, Micaroni M, Morgan GP, Jones N, Kamykowski JA, Wilkins N, Pan TH, Marsh BJ. 2012. Electron tomography reveals Rab6 is essential to the trafficking of transGolgi clathrin and COPI-coated vesicles and the maintenance of Golgi cisternal number. Traffic 13:727-744, doi:10.1111/j.1600-0854.2012.01343.x

Suda Y, Kurokawa K, Hirata R, Nakano A. 2013. Rab GAP cascade regulates dynamics of Ypt6 in the Golgi traffic. Proc Natl Acad Sc USA 110:18976-18981, doi:10.1073/ pnas. 1308627110

Sudhof TC. 2013. Neurotransmitter release: the last millisecond in the life of a synaptic vesicle. Neuron 80: 675-690, doi:10.1016/j.neuron.2013.10.022

Taheri-Talesh N, Horio T, Araujo-Bazan L, Dou X, Espeso EA, Penalva MA, Osmani SA, Oakley BR. 2008. The tip growth apparatus of Aspergillus nidulans. Mol Biol Cell 19:1439-1449, doi:10.1091/mbc.E07-05-0464

— - Xiong Y, Oakley BR. 2012. The functions of myosin II and myosin $\mathrm{V}$ homologs in tip growth and septation in Aspergillus nidulans. PloS one 7:e31218.

Takeshita N, Manck R, Grun N, de Vega SH, Fischer R. 2014. Interdependence of the actin and the microtubule cytoskeleton during fungal growth. Curr Op Microbiol 20:34-41, doi:10.1371/journal.pone.0031218.s012

Valdez-Taubas J, Pelham HR. 2003. Slow diffusion of proteins in the yeast plasma membrane allows polarity to be maintained by endocytic cycling. Curr Biol 13:16361640, doi:10.1016/j.cub.2003.09.001

Veenendaal T, Jarvela T, Grieve AG, van Es JH, Linstedt AD, Rabouille C. 2014. GRASP65 controls the cis Golgi integrity in vivo. Biol Open 3:431-443, doi:10.1242/bio. 20147757

Wang Y, Seemann J, Pypaert M, Shorter J, Warren G. 2003. A direct role for GRASP65 as a mitotically regulated Golgi stacking factor. EMBO J 22:3279-3290, doi:10.1093/ emboj/cdg317

Wassmer T, Attar N, Harterink M, van Weering JR, Traer CJ, Oakley J, Goud B, Stephens DJ, Verkade P, Korswagen HC, et al. 2009. The retromer coat complex coordinates endosomal sorting and dynein-mediated transport, with carrier recognition by the trans-Golgi network. Develop Cell 17:110-122, doi:10.1016/j.devcel.2009.04.016

Wedlich-Soldner R, Schulz I, Straube A, Steinberg G. 2002. Dynein supports motility of endoplasmic reticulum in 
the fungus Ustilago maydis. Mol Biol Cell 13:965-977, doi:10.1091/mbc.01-10-0475

Wei JH, Seemann J. 2010. Unraveling the Golgi ribbon. Traffic 11:1391-1400, doi:10.1111/j.1600-0854.2010. 01114.x

Whyte JR, Munro S. 2001. The Sec34/35 Golgi transport complex is related to the exocyst, defining a family of complexes involved in multiple steps of membrane traffic. Develop Cell 1:527-537, doi:10.1016/S1534-5807 (01) 00063-6

Wong M, Munro S. 2014. Membrane trafficking. The specificity of vesicle traffic to the Golgi is encoded in the golgin coiled-coil proteins. Science 346:1256898, doi:10.1126/ science. 1256898

Wooding S, Pelham HR. 1998. The dynamics of golgi protein traffic visualized in living yeast cells. Mol Biol Cell 9:2667-2680, doi:10.1091/mbc.9.9.2667
Wright J, Kahn RA, Sztul E. 2014. Regulating the large Sec7 ARF guanine nucleotide exchange factors: the when, where and how of activation. Cell Mol Life Sci 71:3419-3438, doi:10.1007/s00018-014-1602-7

Yang Y, El-Ganiny AM, Bray GE, Sanders DA, Kaminskyj SG. 2008. Aspergillus nidulans hypB encodes a Sec7-domain protein important for hyphal morphogenesis. Fungal Genet Biol 45:749-759, doi:10.1016/j.fgb.2007.11.005

Zhang J, Tan K, Wu X, Chen G, Sun J, Reck-Peterson SL, Hammer JA 3rd, Xiang X. 2011. Aspergillus myosin-V supports polarized growth in the absence of microtubule-based transport. PloS one 6:e28575.

Zhou W, Chang J, Wang X, Savelieff MG, Zhao Y, Ke S, Ye B. 2014. GM130 is required for compartmental organization of dendritic golgi outposts. Curr Biol 24:1227-1233, doi:10.1371/journal.pone.0028575. s001 